IZA DP No. 6403

Compulsory Schooling Reforms, Education and Mortality in Twentieth Century Europe

Christina Gathmann

Hendrik Jürges

Steffen Reinhold

March 2012 


\title{
Compulsory Schooling Reforms, Education and Mortality in Twentieth Century Europe
}

\author{
Christina Gathmann \\ University of Heidelberg, \\ CESifo and IZA \\ Hendrik Jürges \\ University of Wuppertal

\section{Steffen Reinhold} \\ University of Mannheim
}

\author{
Discussion Paper No. 6403 \\ March 2012
}

\author{
IZA \\ P.O. Box 7240 \\ 53072 Bonn \\ Germany \\ Phone: +49-228-3894-0 \\ Fax: +49-228-3894-180 \\ E-mail: iza@iza.org
}

\begin{abstract}
Any opinions expressed here are those of the author(s) and not those of IZA. Research published in this series may include views on policy, but the institute itself takes no institutional policy positions.

The Institute for the Study of Labor (IZA) in Bonn is a local and virtual international research center and a place of communication between science, politics and business. IZA is an independent nonprofit organization supported by Deutsche Post Foundation. The center is associated with the University of Bonn and offers a stimulating research environment through its international network, workshops and conferences, data service, project support, research visits and doctoral program. IZA engages in (i) original and internationally competitive research in all fields of labor economics, (ii) development of policy concepts, and (iii) dissemination of research results and concepts to the interested public.
\end{abstract}

IZA Discussion Papers often represent preliminary work and are circulated to encourage discussion. Citation of such a paper should account for its provisional character. A revised version may be available directly from the author. 


\section{ABSTRACT \\ Compulsory Schooling Reforms, Education and Mortality in Twentieth Century Europe*}

Education yields substantial non-monetary benefits, but the size of these gains is still debated. Previous studies, for example, report contradictory effects of education and compulsory schooling on mortality - ranging from zero to large mortality reductions. Using data from 19 compulsory schooling reforms implemented in Europe during the twentieth century, we quantify the mean mortality effect and explore its dispersion across gender, time and countries. We find that men benefit from compulsory education both in the shorter and longer run. In contrast, compulsory schooling reforms have little or no effect on mortality for women.

JEL Classification: $\quad$ I12, I21, I28

Keywords: compulsory schooling, education, mortality, Europe

Corresponding author:

Christina Gathmann

Department of Economics

University of Heidelberg

Bergheimerstraße 20

69115 Heidelberg

Germany

E-mail: christina.gathmann@awi.uni-heidelberg.de

\footnotetext{
" We thank Nicole Schneeweis and Laurent Lequien as well as participants at the SOLE Meeting 2011, the ZEW Workshop on "Health and Human Capital" and the University of Augsburg for valuable comments and suggestions. All remaining errors are our own.
} 


\section{Introduction}

The returns to education have long been of central interest to researchers and policy-makers alike. More recently, attention has turned to the various nonpecuniary benefits of education that accrue above and beyond the monetary returns. Among those are more stable marriages, lower crime rates, better parenting and improvements in health (e.g. Haveman and Wolfe, 1984; Oreopoulos and Salvanes, 2011). Many researchers believe these additional benefits are even larger than the monetary gains from education.

The size of these additional gains from education is however, still debated. For example, it is well-known that education shows a strong empirical correlation with various health measures and mortality (Grossman 2006; Cutler and Lleras-Muney, 2010). A key challenge however, is to find credible variation in education to identify its causal effect on mortality or other health measures.

Some studies have exploited changes in compulsory schooling laws which generate exogenous variation in schooling at the lower end of the educational distribution. Using data from different countries and time periods, the literature finds conflicting results. Lleras-Muney (2005) finds that compulsory schooling reduces 10-year mortality in the US by as much as 6 percentage points. Similarly, Cipollone and Rosolia (2009) and van Kippersluis et al. (2011) report significant, albeit much smaller effects for Italy and the Netherlands. Other studies find few or no effects of compulsory schooling on mortality in France (Albouy and Lequien, 2009), the United Kingdom (Clark and Royer, 2010) and even the United States (Mazumder, 2008). It is unclear whether these differences are the result of the data sources, the estimation approach or the particular characteristics of the reform or country it is implemented in.

In this article, we use a different approach to quantify the non-monetary returns of compulsory schooling (and education more broadly). Rather than estimating the effect of a single reform in a specific country, we estimate the 
average mortality effect of all reforms that have been implemented in Europe over the course of the twentieth century.

Our multi-country setting has several advantages. First, because our data is harmonized across time and space, we can compare the mortality effects of compulsory schooling legislation across different periods and countries. The comparison may explain why previous studies, which rely on different data sources, mortality measures and estimation methods, have found such divergent results. Second, the estimates have broader validity as they are less dependent on the specific features of a single reform or the particular circumstances in a country. Our analysis reveals whether compulsory schooling reforms have any effect on mortality across a wide range of settings. ${ }^{1}$ Finally, we can use our analysis to explore the heterogeneity of treatment effects across countries and time periods. For example, the health benefits of education might be more pronounced in countries suffering from high mortality rates at the time of the schooling reform. As such, our results help to understand in which settings compulsory schooling may have beneficial effects on health.

Our analysis proceeds in three steps. We first investigate whether there is any effect of compulsory schooling reforms on mortality, i.e. the reduced-form effect. Using a regression discontinuity design on cohort-level data, we compare mortality rates for cohorts who are just affected (or just not affected) by the compulsory schooling reform. These reduced-form results are our preferred set of estimates because they can be estimated for all reforms implemented across Europe since the beginning of the $20^{\text {th }}$ century.

For a subsample of reforms, we analyze the causal effect of an additional year of schooling on mortality. Here, we use the reform indicators as an instrument for educational attainment of cohorts just affected (or just not affected) by the

\footnotetext{
${ }^{1}$ Our multi-country approach also reduces concerns about publication bias when studies that find a positive and sizeable effect of compulsory schooling mandates on educational attainment are more likely to be published than those with negative or zero effects on educational attainment.
} 
reform. Because the data on educational attainment are taken from a different source than the mortality data, we implement a two sample 2SLS estimator (see Angrist and Krueger, 1992; Inoue and Solon, 2010). The first-stage then tells us whether compulsory schooling reforms in Europe raise educational attainment (i.e. their effect on schooling decisions and the degree of compliance among affected cohorts). The second-stage estimates reveal the health benefits of an additional year of education which can then be compared to other estimates of non-monetary returns to education.

In the final step, we perform a meta-analysis to pool the evidence and estimate the mean effect and its dispersion across reforms, time periods and countries. Meta-analysis is widely used in other social sciences and medicine. It has also become a common tool in economics recently to pool evidence from multiple studies and test for publications bias (see Ashenfelter et al., 1999; Card and Krueger, 1995; or Chetty et al. 2012 for examples).

We have three main findings: overall, we find that compulsory schooling reduces mortality for men, but not for women. For men, compulsory schooling mandates imply a reduction in the relative risk of dying (between age 18 and 38) by $2.88 \%$. These mortality effects are surprisingly similar for longer-run mortality. Men have a $2.88 \%$ lower relative risk of dying between the ages 18 and 48 (30-year mortality) and a 2.67\% lower relative risk of dying between the ages 18 and 58 (40-year mortality). Women in contrast do not benefit from compulsory schooling in terms of reduced mortality irrespective of the age span analyzed.

Further, we show that the compulsory schooling reforms in our sample increased average educational attainment by 0.42 years for men and 0.35 years for women. These first-stage effects are comparable to the 0.3 years found for a different set of European schooling reforms (Brunello, Fort and Weber, 2009). The two-sample 2SLS estimates provide a very similar picture than the reduced-form, although the estimates are considerably noisier. As before, there is no discernible effect for women, but men benefit from additional education. 
Specifically, an additional year of education reduces, for example, the average 20-year mortality rate for men by $2.0 \%$.

Finally, we find substantial heterogeneity in mortality effects. We already noted the differences between men and women. Mortality reductions also seem to vary systematically across countries. For example, the Belgian reform of 1919, which raised schooling levels from 3 to 8 years of education, reduced the 20 -year mortality for men by as much as $10.7 \%$. Other reforms, like the Spanish reform of 1970, seem to have no health benefits even for men. Interestingly, the heterogeneity across countries is largest for 20-year mortality rates and smaller for longer-run mortality rates (even holding the set of reforms constant). The most consistent reductions in mortality (for both shorter and longer-run mortality) are found for the 1919 reform in Belgium (for men) and the 1928 reform in the Netherlands (for women). Both reforms increase compulsory schooling by more than one year.

Also, mortality reductions for men are somewhat larger for reforms implemented prior to 1930 (that is, Denmark in 1903, Belgium in 1919 and the Netherlands in 1928). On average, these reforms reduce male mortality between the ages 18 and 38 by $6.4 \%$. In part, the early reforms might have been more successful in reducing mortality because schooling levels were increased by more than one year (2 years in the Danish reform of 1903 and even 5 years in the Belgian reform of 1919). Reforms that were implemented after 1970 in contrast, reduce male mortality by only 1.2\% (but all later reforms increased compulsory education by just one year).

Taken together, we contribute to the existing literature in a number of ways. Our results support recent evidence showing modest, yet persistent health benefits for men. We further document that health benefits of compulsory schooling and education more generally, differ substantially by gender. Most studies using compulsory schooling reforms in contrast estimate the health 
effects for men and women jointly or only analyze men. ${ }^{2}$ In addition, we show that not all compulsory schooling reforms are created equal though all typically affect the lower end of the educational distribution. Some lead to large mortality reductions for men, for example, in the Low Countries. Others, like most reforms in Southern Europe, do not seem to have any effect on mortality. Our evidence confirms that the conflicting results reported in the previous literature are not a coincidence but a systematic feature of the reform setting and its implementation. Finally, we also contribute to the literature on the non-monetary benefits of education. We quantify for the first time that the health benefits of education are substantial in Europe - at least for men.

\section{Data Sources}

We base our analysis on 19 national reforms of compulsory schooling that were implemented across Europe between 1903 and 1976. The reforms cover 12 European regions or countries: Austria, Belgium, Denmark, Sweden, England and Wales, Scotland, Northern Ireland, France, Ireland, Italy, Netherlands and Spain. ${ }^{3}$

Compulsory schooling laws generate exogenous variation in educational attainment at the lower end of the schooling distribution. In our setting, years of compulsory schooling increase from as low as 3 years (Belgium in 1919) to as much as 10 years (France in 1937 or the Netherlands in 1968). The Italian reform in 1963, for example, increases compulsory schooling from 5 to 8

\footnotetext{
${ }^{2}$ One exception that also finds no health effects for women, but positive health effects for men is by Kemptner, Jürges and Reinhold (2011).

${ }^{3}$ Several other countries (like Finland, Germany or Portugal, for example) also introduced compulsory schooling reforms during the twentieth century. The reforms in Finland and Germany were implemented at the subnational level but our mortality data is only available at the national level. Portugal increased compulsory schooling both in 1956 (boys)/1960(girls) and 1964. The proximity of the two reforms introduces confounding effects that would bias our estimates. Econometrically speaking, the assumption that no other event above and below the threshold will affect education and mortality will not be violated because some cohorts will be reasonably close to both reforms. We therefore excluded the reforms in Finland, Germany and Portugal from our analysis.
} 
years affecting all children born in 1949 or later. Table 1 lists key features of each reform (like the year of implementation and minimum schooling levels), the birth year of the first cohort affected by the reform and their respective mortality rates. More detailed information on each reform is provided in the data appendix.

To analyze whether the schooling reforms have any impact on educational attainment, we use data from three surveys: the European Social Survey (ESS), the International Social Survey Programme (ISSP) and the Survey of Health, Ageing and Retirement in Europe (SHARE). The ESS and ISSP are repeated cross-sectional surveys based on nationally representative samples of the population aged 18 and older (15 and older in the ESS) in more than 20 countries (ESS) and more than 30 countries (ISSP). SHARE is based on nationally representative samples of the population aged 50 and older in 15 European countries. ${ }^{4}$

The European Social Survey (ESS) and International Social Survey Programme (ISSP) mainly elicit social attitudes and changes in values, but also collect demographic information such as educational attainment, gender and the year of birth. We use the five available waves of the ESS that have been collected biannually since 2002 with sample sizes between 1,500 and 3,000 individuals in each country and wave. For the ISSP, we use all twentyfive waves that have been collected annually since 1985. The sample sizes in the ISSP vary between 1,000 and 3,000 individuals for each wave and country. Finally, SHARE collects information on health and socio-economic variables, but also on year of birth, gender and educational attainment. So far, three waves are available which have been collected biannually between 2004 and

\footnotetext{
${ }^{4}$ We use data in the European Social Survey (ESS) for Belgium, Denmark, France, Netherlands, Portugal, Spain, Sweden, and the United Kingdom; in the International Social Survey Programme (ISSP), we use the data for Austria, Belgium, Denmark, France, Great Britain, Ireland, Italy, Netherlands, Northern Ireland, Portugal, Spain and Sweden. In the Survey of Health, Ageing and Retirement in Europe (SHARE), we use the data for Austria, Belgium, Denmark, France, Italy, Netherlands, Spain and Sweden.
} 
2008. The sample sizes range from 1,000 to 4,000 individuals in each participating country and wave.

We pool data across surveys and all available waves and calculate average educational attainment (measured in years of schooling) for all cohorts around the reform date separately by gender and country. ${ }^{5}$ Overall, we have information on educational attainment for 27,237 women and 21,979 men once we restrict the sample to the 10 cohorts before and 10 years after each reform.

To investigate how compulsory schooling reforms affected mortality across Europe, we use data from the Human Mortality Database (Human Mortality Database, 2011). The database contains, among others, age-specific mortality rates for over 30 countries from cohorts born as early as the late $17^{\text {th }}$ century until today. ${ }^{6}$ The database uses a common methodology to convert death and birth counts (from official vital statistics) as well as population counts (mostly from national censuses) into mortality rates by year, age and birth cohort. ${ }^{7}$

To trace mortality over the life cycle for cohorts around the reform date, we calculate the probability that an 18-year old dies within 20, 30, 40 or 50 years. We label these 20-, 30-, 40- or 50-year mortality rates. We choose age 18 as our starting age because compulsory schooling (affected by the reforms) is completed by then. The 1947 compulsory schooling reform in England and Wales, for instance, increases the number of compulsory years from 8 to 9 . The reform affects all cohorts turning 14 in 1947 or later. As a consequence,

\footnotetext{
${ }^{5}$ In the ESS and ISSP, educational attainment is measured as the highest level of schooling completed. The answer categories are country-specific and later recoded according to the International Standard Classification of Education (ISCED). In SHARE, educational attainment is measured similarly and recoded as years of education.

${ }^{6}$ Data for our countries and regions of interest are available for the following birth cohorts: Austria (1871-1980), Belgium (1765-1979), Denmark (1764-1979), England and Wales (1764-1979), France (1737-1979), Ireland (1871-19709), Netherlands (1777-1979), Northern Ireland (1847-1979), Portugal (1846-1979), Scotland (1777-1979), Spain (1822-1979) and Sweden (1676-1980).

7 The database is the result of a joint effort of researchers at the University of California, Berkeley and the Max-Planck-Institute in Rostock, Germany. See Wilmoth et al. (2007) and the website www.mortality.org for further details of the raw data and the methodology used to calculate harmonized age- and cohort-specific death rates across countries.
} 
the first cohort affected is born in 1933 and turned 18 in 1951. The 20-year mortality rate is then computed as one minus the probability that an individual survives until 1971 conditional on being alive in 1951. We calculate mortality rates over longer time spans, for other cohorts and schooling reforms accordingly.

\section{Empirical Strategy}

\subsection{Reduced Form Estimates}

We first explore whether there is any effect of compulsory schooling reforms on mortality, i.e. the reduced-form effect. To do so, we compare mortality rates of cohorts just affected by the reforms to mortality rates of earlier cohorts that are unaffected. The reduced-form approach mirrors empirical specifications common in regression discontinuity designs (see Imbens and Lemieux 2008; Lee and Lemieux, 2010 for surveys). Specifically, we estimate the following model separately for each country and gender:

$$
\ln \left(\frac{m_{c}^{x}}{1-m_{c}^{x}}\right)=\alpha+\beta_{R D} D_{c}+\gamma_{1} Y_{c}+\gamma_{2} Y_{c}^{2}+\gamma_{3}\left(D_{c} \times Y_{c}\right)+\gamma_{4}\left(D_{c} \times Y_{c}^{2}\right)+u_{c}
$$

where $m_{C}$ is the $x$-year mortality rate of cohort $c . D_{C}$ is a dummy equal to one if the cohort is affected by the reform and zero otherwise. We exclude the first cohort potentially affected as not everybody in that cohort might have been covered by the reform. The baseline results use ten cohorts before and ten cohorts after the reform. We further probe the choice of bandwidth in our robustness analyses (see Section 4.4. below). To adjust flexibly for cohort trends in mortality, we use a quadratic polynomial in the year of birth $Y_{C}$ (measured relative to the first cohort affected). The quadratic trend is allowed to differ on either side of the reform threshold. Note that estimating the effects for each country separately, we also account flexibly for country-specific cohort trends and for heterogeneous treatment effects across countries. 
Furthermore, we run separate analyses for male and female mortality to allow for differences in compliance with the reform and differential mortality trends across genders.

Our parameter of interest $\beta_{R D}$ identifies the mortality effect of each compulsory schooling reform among compliers (who stay in school longer because of the new legislation than they would have stayed without the reform). Under positive compliance and monotonicity, the reduced-form effect identifies whether there is any effect of schooling on mortality. Our results below report odds ratios, $\exp \left(\beta_{R D}\right)$, which (for values close to one) approximate relative annual mortality risks.

The identifying assumption we require is that cohorts born just above and just below the threshold face similar mortality risks conditional on flexible cohort trends but differ in their completed years of education. ${ }^{8}$

\subsection{Two Sample 2SLS Estimates}

For a subset of reforms, we have information on educational attainment of the affected cohorts from the ESS, ISSP and SHARE. ${ }^{9}$ We use these additional data to implement a 2SLS estimator of the returns to education on mortality. The 2SLS estimator provides two additional insights: the first-stage estimates show how the compulsory schooling reforms affected educational attainment in each country - and whether these effects are plausible. Like the reducedform estimates, we estimate the first stage with data aggregated to the cohort, gender and country level. ${ }^{10}$ Hence, we estimate a variant of equation (1), where the dependent variable is now average educational attainment for cohort

\footnotetext{
${ }^{8}$ Differential international migration might be one potential source of bias. Clark and Royer (2010) however, find little evidence for confounding effects from migration in the United Kingdom.

${ }^{9}$ We have data on educational attainment covering the following reforms: Austria (1966), Denmark (1971), England and Wales (1947 and 1973), France (1937 and 1967), Ireland (1972), Italy (1963), Netherlands (1928, 1950 and 1973), Northern Ireland (1957), Spain (1970) and Sweden (1962).

${ }^{10}$ Using the aggregate data (rather than the individual-level survey data) accounts for clustering by birth cohort and produces conservative standard errors.
} 
$c$ and the estimation is performed separately by gender and country. The second-stage in turn identifies the causal effect of one additional year of compulsory schooling on mortality among those affected by the reform (assuming nonzero compliance and monotonicity as before).

The 2SLS estimates will differ from the reduced-form estimates for at least two reasons: if the reform affects only few students or if not all students comply with the new compulsory schooling law, years of schooling will increase by less than the compulsory schooling reform mandates. In that case, the 2SLS estimate will be larger in absolute terms (more negative) than the reduced-form estimate, so $\left|\beta_{2 S L S}\right|>\left|\beta_{R F}\right| .^{11}$ In addition, the 2SLS and reducedform estimates are different because several reforms in Europe increased compulsory schooling by several years (see Table 1). If the reform increases average education attainment by more than one year, we expect the reducedform effect on mortality to be larger in absolute terms (more negative) than the 2SLS estimates, so $\left|\beta_{\mathrm{RF}}\right|>\left|\beta_{2 S L S}\right|$. Note that we can implement the 2SLS estimator only for the 12 reforms for which we have information on educational attainment for all cohorts around the threshold.

To implement the 2SLS estimator, we estimate the following model:

$$
\ln \left(\frac{m_{c}^{x}}{1-m_{c}^{x}}\right)=\beta_{0}+\beta_{2 S L S} E d u c_{c}+\tilde{\gamma}_{1} Y_{c}+\tilde{\gamma}_{2} Y^{2}+\tilde{\gamma}_{3}(D \times Y)+\tilde{\gamma}_{4}\left(D \times Y^{2}\right)+u_{c}
$$

where we use the indicator for compulsory schooling reforms $D_{C}$ as an instrument for average years of schooling $E d u c_{c}$ in the first stage. As before, we control for a local quadratic polynomial to capture secular trends in educational attainment and estimate the model separately for each country and gender to account flexibly for country- and gender-specific differences. In

\footnotetext{
${ }^{11}$ With partial compliance, the first stage estimate is smaller than one. Because the 2SLS estimator can be written as the ratio of the reduced-form estimator divided by the first-stage estimator, partial compliance implies that the 2SLS estimate of equation (1) will be larger in absolute terms than the reduced-form estimate.
} 
addition, we also include survey dummies to adjust for differences in measured educational attainment across the three data sources.

The 2SLS estimator we implement is based on two different samples: the information on educational attainment is taken from the ESS, ISSP and SHARE surveys, while the mortality data come from the Human Mortality Database. The two-sample 2SLS estimator is consistent as long as the two samples are drawn from the same population (Inoue and Solon, 2010). ${ }^{12}$

An important practical issue is how to obtain correct standard errors, because the first-stage and second-stage estimates are typically drawn from different population samples (see Angrist and Krueger, 1992; Inoue and Solon, 2010). The modeling choices we made in our setting, however, ensure that we obtain correct standard errors. The estimates in the first and second stage are based on the exact same set of reforms and years (since we estimate equation (1) separately for each reform). We further impose the restriction that the first and second stages use the same set of observations for each reform. Therefore, the marginal distributions of the instrument and control variables are exactly the same across the two samples. ${ }^{13}$

\subsection{Meta-Analysis of Reform Effects}

One advantage of our data is that we can estimate the average effect of all compulsory schooling reforms implemented in Europe - independent of the particular circumstances of a reform or the country in which it is implemented. To estimate the mean effect (and its dispersion), we perform meta-analyses for the pooled reduced-form ( $\left.\beta_{R D}\right)$ and the pooled two-sample 2SLS estimates (

\footnotetext{
${ }^{12}$ Note that the 2 SLS and IV estimator no longer coincide when two different data samples are used. Inoue and Solon (2010) recommend the 2SLS estimator, as is used here, because it corrects for differences in the distribution of the instrument across the two samples.

${ }^{13}$ An alternative approach would be not to impose the same marginal distribution across the two samples. This approach might generate more efficient estimates (since we use more information) but we would then need a bias-correction for the variance-covariance matrix like the Murphy-Topel estimator (originally designed to correct for generated regressor bias) suggested by Inoue and Solon (2010).
} 
$\beta_{2 S L S}$ ), respectively. Meta-analysis is commonly used in the medical sciences to determine whether treatment effects vary across experimental studies run at different locations and time periods. Here, we use meta-analysis to explore the heterogeneity of European compulsory schooling reforms and probe the external validity of previous mortality estimates.

When pooling the evidence from different reforms, we need to weigh individual reform estimates to generate an average effect. Weighting can be done either using random or fixed effects (see, for example, Borenstein et al. 2009). The fixed effects approach assumes that there is no heterogeneity of mortality effects in the underlying population; it should be used when the heterogeneity of estimates is low. Fixed effects assign each reform a weight equal to the inverse of the country's sample variance. When treatment effects vary a lot across studies, random effects are more appropriate. The random effect approach assumes that reform effects are drawn from a normal distribution. ${ }^{14}$ Compared to the fixed effects approach, the weights assigned to each study give less weight to outliers - very large or very small study effects. To determine the heterogeneity of effects across countries (and hence the choice between fixed and random effects), we follow the literature and use as our criterion the I-squared. This measure is defined as follows:

$$
I-\text { squared }=\max \left(0, \frac{Q-d f}{Q} * 100\right)
$$

where $Q=\sum_{i=1}^{k} w_{i}\left(\beta_{i}-\bar{\beta}_{i}\right)^{2}$. The weights $w_{i}$ are the inverse of the sampling variance of study $i, \beta_{i}$ is the treatment effect in study $i$, and $\overline{\beta_{i}}$ is the mean

14 In particular, it is assumed that reform effects $\beta_{i}$ are drawn from the following distributions: $\beta_{i} \sim N\left(\theta_{i}, \sigma_{i}^{2}\right) ; \theta_{i} \sim N\left(\mu, \tau^{2}\right)$. The goal in the random effects approach is to estimate the mean of the distribution of effects, $\mu$, and not a single "true" effect. The weights for the random effects analysis are defined as $w^{\text {random }}=1 /\left(\sigma_{i}^{2}+\tau^{2}\right)$. This formula shows that less weight is given to "outliers" compared to the fixed effects analysis which weighs by the inverse of the sampling variance, $\sigma_{i}^{2}$. 
effect across all studies. In (3), $d f$ denotes the number of reforms (defining the degrees of freedom). I-squared varies from $0 \%$ to $100 \%$ where higher values indicate more treatment effect heterogeneity (favoring a random effects approach). Values of 50\% (75\%) are considered thresholds for moderate (large) treatment effect heterogeneity (for example, Higgins et al., 2003).

\section{Empirical Results}

\subsection{Reduced Form Effect of Reforms on Mortality}

We first investigate whether compulsory schooling reforms have any effect on mortality. Table 2 reports odds ratios and 95\% confidence intervals for the reform effect on mortality in the short run (ages 18-38 and ages 18-48) and longer-run (ages 18-58 and ages 18-68).

For 20-year mortality, 14 out of the 19 odds ratios are smaller than one indicating a reduction in mortality. For six reforms, we find statistically significant reform effects (at the 5\% level): the 1919 reform in Belgium $(\mathrm{OR}=0.90)$, the 1957 reform in Northern Ireland $(\mathrm{OR}=0.93)$, the 1966 reform in Austria (OR=0.94), the 1967 reform in France (OR=0.95), the 1973 reform in England and Wales (OR=0.98) and the 1976 reform in Scotland $(\mathrm{OR}=0.94)$. To investigate longer-run effects, we analyze 30-, 40-, and 50-year mortality rates for reforms where we have data for 10 cohorts above and below the threshold. We find that increases in compulsory schooling reduce longer-term mortality among men as well. For 30-year mortality rates, for example, 10 out of the 14 odds ratios indicate a reduction in mortality; for 40-year mortality rates, we find that five out of eight odds ratios show a reduction in mortality. For 50-year mortality, five out of six estimates of the reform have an odds ratio close to one (indicating a zero effect). Only the 1919 reform in Belgium continues to have a statistically negative effect on male mortality even in the long-run. 
Overall, the most consistent mortality reductions for men are observed for the 1919 reform in Belgium and the 1928 reform in the Netherlands. How large are these mortality benefits for men? The Belgian reform, for example, implies a reduction in male mortality by $5.6 \%$ (for 30 -year mortality), $4.6 \%$ (for 40 year mortality) and $4.3 \%$ (for 50 -year mortality) respectively. ${ }^{15}$ These effects are substantial; yet, we also need to take into account that the reform raised compulsory schooling by 5 years. Even the Dutch reform, which raised compulsory education by 2 years, however, reduced male mortality by a sizeable $4.4 \%$ (for 30 year-mortality) and 6.6\% (for 40-year mortality) respectively.

One interpretation of these findings is that compulsory schooling reforms only have an effect in very few countries (where reforms raised compulsory schooling by several years). An alternative interpretation is that the data are too noisy to detect an effect in some countries (where odds ratios are below one but not statistically significant). To explore this second explanation, we now pool the data across countries and use meta-analysis to estimate a joint effect of all compulsory schooling reforms in Europe. Figure 1 shows a forest plot of the individual reform effects and the pooled estimate for 20-year mortality rates (for which we have data for all 19 reforms). The pooled estimate is based on a random effects approach since the I-squared indicates substantial heterogeneity across estimates (i.e. we can reject the null hypothesis of no heterogeneity with $\mathrm{p}<0.05) .{ }^{16}$ The grey square represents the weight of each reform in the pooled estimation. The pooled estimate (shown as a dashed line) across all reforms suggests an overall reduction in male mortality by $2.8 \%(\mathrm{OR}=0.972) .{ }^{17}$ We find very similar and also statistically significant effects for 30- and 40-year mortality rates, but no significant pooled effect for 50-year mortality rates (shown at the bottom of Table 2).

\footnotetext{
${ }^{15}$ The 40 -year mortality effect in percent is $(1 / 0.956-1) * 100=4.6 \%$ (as the odds ratio is smaller than one). The effects on 30- and 50-year mortality rates are calculated analogously. ${ }^{16}$ We obtain similar results if we use fixed effects instead. Results are available upon request.

${ }^{17}$ The odds ratio of 0.972 implies a reduction in 20 -year mortality of $(1 / 0.972-1) * 100=2.8 \%$.
} 
Overall, compulsory schooling reforms seem to have substantial health benefits for men. In contrast, we find basically no effect for women (as shown in Table 3). For 20-year mortality, odds ratios of 12 out of 19 reforms are below one indicating a reduction in mortality. Most estimates, however, are not statistically significant. Statistically significant reductions in mortality rates are only found the 1928 reform in the Netherlands and the 1972 reform in Northern Ireland. Longer-run mortality shows a very similar pattern: 5 out of 14 odds ratios (for 30-year mortality) and 5 out of 8 odds ratios (for 40-year mortality) are below one - but only one or two are statistically significant. The one reform that consistently reduces female mortality over the life-cycle is the 1928 reform in the Netherlands. This reform reduces female mortality by $12.2 \%$ (for 20 -year mortality), 6.3\% (for 30-mortality) and $5.6 \%$ (for 40 -year mortality) respectively. These effects are substantial. Yet again, we need to keep in mind that compulsory schooling was raised by 2 years and the reform likely had a non-trivial effect on average educational attainment.

The meta analysis (shown in Figure 2 and the bottom of Table 3) also suggests no coherent effect of European compulsory schooling reforms for women. The pooled effects are very close to one and none is statistically significant. Hence, compulsory schooling reforms as implemented in Europe during the twentieth century seem to have little non-monetary gains (in terms of a longer life) for women.

The reduced-form estimates also suggest substantial heterogeneity of mortality effects across gender, countries and time periods. We have already mentioned the differences between men and women. There are also large differences across reforms and countries. For example, the Belgian reform of 1919, which raised schooling levels from 3 to 8 years of education, reduced the 20-year mortality for men by as much as $10.7 \%$. Other reforms, like the Spanish reform of 1970, seem to have no health benefits even for men. Interestingly, the heterogeneity in effects across countries is substantially larger for the 20year mortality rates than for longer-run mortality rates. The more 
heterogeneous effects for short-run mortality remain even when keeping the set of reforms constant. For 40-year mortality, for example, the odds ratios range from 0.938 (the Dutch reform of 1950) to 1.129 (the French reform of 1937); for the same set of reforms, the odds ratios for 20-year mortality rates range from 0.903 (the Belgium reform of 1919) to 1.348 (the French reform of 1937).

Also, mortality reductions for men are somewhat larger for reforms implemented prior to 1930 (that is, Denmark in 1903, Belgium in 1919 and the Netherlands in 1928). On average, these reforms reduce male mortality between the ages 18 and 38 by 6.4\%. Reforms that were implemented after 1970 in contrast, reduce male mortality between the ages 18 and 38 by only $1.2 \%$. In part, the larger mortality reductions are explained by the fact that schooling levels in the early reforms were often raised by several years (2 years in the Danish reform of 1903 and even 5 years in the Belgian reform of 1919). Alternatively, mortality improvements might have been larger for the early reforms because mortality rates were still at high levels early in the twentieth century. Yet, in additional meta-analytic regression analyses, we do not find any significant relationships between the sign of the coefficient $\beta$ in equation (1), the year of the reform and baseline mortality just prior to the reform (not reported here).

\subsection{The Impact of the Reforms on Educational Attainment}

We next investigate how compulsory schooling reforms affect educational attainment for the subset of reforms for which we have data on years of schooling available. Table 4 reports the results of the first stage regressions. The estimates from our data are shown in the column labeled "First stage for 2SLS”, the corresponding standard error in the column to the right.

On average, the compulsory schooling reforms in Europe increases years of education by 0.42 years for men and 0.35 years for women (see pooled estimates at the bottom of Table 4). Individually, most reforms have no 
statistically significant effect on schooling and would not pass the usual diagnostic checks for weak instruments. ${ }^{18} \mathrm{~A}$ few reforms show a negative effect on educational attainment though none of them are statistically significant. $^{19}$

That some first-stage estimates are noisy should not surprise us given the data available. We use household surveys where the number of individuals in each cohort-year-gender cell is relatively small (compared to the large administrative data sets or census data that are available in some countries). As a consequence, we have substantial sampling variability in the measure of educational attainment which will inflate our standard errors in the first stage. In addition, we aggregate the data to the cohort-year-gender level in order to be consistent with the mortality data used in the second stage. Finally, we restrict the first stage to only 10 birth cohorts above and below the reform threshold to reduce concerns of omitted variable bias (as the result of shocks that occurred many years before or after the reform).

The weak first-stage estimates therefore are likely the consequence of small samples and potential measurement error in educational attainment in our data. Given that others have successfully used multiple European compulsory schooling reforms to study its effects on wages (Brunello, Fort and Weber, 2009) or fertility (Fort, Schneeweis and Winter-Ebmer, 2011) it does not indicate that the compulsory schooling reforms had no effect on educational attainment. We compare our first-stage results to those obtained in the literature to support our claim that the European compulsory schooling reforms had an effect on educational attainment (and are therefore a useful instrument to analyze the causal effect of education on mortality). The righthand side of Table 4 shows all available estimates of the effect of compulsory

\footnotetext{
${ }^{18}$ To take one example, the F-statistic for the instrument of the 1973 reform in England and Wales is just 3.2 when estimating the first stage for men which is below the rule-of-thumb value of 10 (in the case of one endogenous variable and one instrument).

${ }^{19}$ Note however, that we are not the only ones finding negative effects of selected compulsory schooling reforms on educational attainment. Levin and Plug (1999) also report a negative effect of compulsory schooling on years of schooling for the 1950 reform in the Netherlands.
} 
schooling reforms on schooling across Europe (under the header "Estimates in the literature”). Note that the estimates taken from the literature are all based on individual-level data of educational attainment and several authors use very large administrative datasets to analyze the effect on education in their particular country (like Albouy and Lequien, 2009; Clark and Royer, 2010; van Kippersluis et al, 2011). ${ }^{20}$ It is thus not surprising that the effects on schooling are more precisely estimated than in our data.

It is reassuring, however, that the average effect of compulsory schooling reforms on educational attainment in the literature is about 0.4 years (pooled over all studies and genders) - which is remarkably similar to our pooled estimates of 0.42 for men and 0.35 for women. Overall then, our first-stage estimates do not seem to be out of line. We thus present in the next section the 2SLS estimates for the effect of one additional year of education on mortality.

\subsection{Two-Sample 2SLS Estimates of Education on Mortality}

Our two-sample 2SLS estimates are based on the subset of reforms for which we have cohort-specific data on both years of education and mortality. We further restrict our analysis to reforms for which the first-stage effect of compulsory schooling on educational attainment is positive. We thus drop reforms with a negative first-stage (like the French reform of 1937 for men or the Swedish reform in 1962 for both men and women, for example). We also need to drop the earliest reforms (the 1903 reform in Denmark and the 1919 reform in Belgium) because we have no evidence about the first-stage effect on education (recall that we estimate the 2SLS separately for each country). The restricted sample now includes the following 9 reforms for men and 10 reforms for women: Netherlands 1928, France 1937 (women only) England and Wales 1947, the Netherlands 1950 (women only) Austria 1966, France

\footnotetext{
${ }^{20}$ Using the aggregate data, we give an equal weight to each cohort in the estimation. In the micro data, the cohorts are weighted according to the number of individuals in that birth cohort responding to the survey.
} 
1967, Spain 1970, Ireland 1972, England and Wales 1973, the Netherlands 1973 and Denmark 1971 (men only).

Figure 3 presents the 2SLS estimates of the effect of education on 20-year mortality for men. Overall the two-sample 2SLS estimates indicate a 2.04\% reduction in relative risk per additional year of schooling for men $(p<10 \%)$. Note that, here, we cannot reject the null hypothesis that the effect of one year of education on mortality is homogenous across reforms and countries. The corresponding reduced-form estimates on the subset of reforms (and the pooled estimates) are shown in Table A1 in the appendix. The overall pattern is very similar across the two estimation methods: both reduced-form and 2SLS estimates suggest that education has beneficial health effects for men. The two-sample 2SLS estimates are however, noisier than the reduced form estimates.

Figure 4 presents the effect on 20-year mortality for women. Mirroring the reduced form estimates (also shown in Table A1 in the appendix), the results for women suggest a zero effect of educational attainment on mortality.

As a final piece of evidence, we compare 2SLS and reduced-form estimates for 30-year mortality. Table 5 shows the same pattern for both men and women yet again. An additional year of education reduces the risk of dying for men by 3.84\%; for women, there is no mortality effect of compulsory schooling reforms or additional education more generally. ${ }^{21}$ Unfortunately, we cannot implement the 2SLS estimator for mortality in the very long-run (40and 50-year mortality). The reason is that data on educational attainment are only available for the more recent reforms for which long-run mortality rates cannot be calculated with the available data.

\subsection{Robustness Checks}

\footnotetext{
${ }^{21}$ For the two-sample 2SLS, the pooled estimate is 0.963 for men; hence, (1/0.963$1)^{*} 100=3.84 \%$.
} 
In this section, we check the robustness of our results to alternative empirical specifications. We start out with the choice of bandwidth around the reform threshold (Lee and Lemieux, 2010). Our identification relies on the assumption that cohorts just affected or just not affected by the reform are similar to each other in every aspect other than the reform. Hence, one would like to restrict the analysis to just a few cohorts left and right of the reform threshold. However, focusing the analysis on very few cohorts also reduces statistical power. The left-hand side of Table A2 for men and A3 for women shows reduced-form estimates using 5 cohorts and 3 cohorts on each side of the reform threshold (rather than the 10 cohorts used in the baseline above).

Our identification also depends on a correct specification of other shocks affecting mortality. In the baseline, we use a local quadratic trend allowing secular changes in mortality to be different before and after the reform threshold. The right-hand side of Table A2 (for men) and Table A3 (for women) show estimates when we use a local linear polynomial or global cubic polynomial instead. As before, we estimate the specifications separately for each reform and each gender.

Using fewer cohorts in the estimation, we still find consistent health benefits of the 1957 reform in Northern Ireland for men. Overall, however, the effects are less precisely estimated and the pooled estimates with 5 and 3 cohorts below and above the threshold are no longer statistically significant for men. For women, the results are also noisier and - like the baseline results -no health benefits from compulsory schooling reforms emerge.

The alternative specifications of cohort-specific trends generate similar results as in the baseline. We find significant effects for a few reforms like the 1957 reform in Northern Ireland or the reforms in the early 1970s in Northern Ireland (1972), England and Wales (1973) and Scotland (1976). The pooled estimates show a similar pattern as well with mortality reductions for men, but not for women. 
Finally, there is some ambiguity how to code the reform in Denmark in the 1970s. Some authors argue that the reform occurred in 1971 while others claim it was implemented only in 1975 (see data appendix for details). Above, we report results where the Danish reform is coded as 1971 and the first cohort affected born in 1957 because we find this information more convincing than the source suggesting 1975 as the reform year. When we code the reform as 1975 instead (and the first cohort affected born in 1961), we find very noisy results for men (see Figure A1) and even an increase in mortality for women (see Figure A2). In sum, our robustness checks support the idea that men benefit from compulsory schooling reforms, while women do not.

\section{Conclusion}

The starting point of our analysis was that there is still no consensus about the size of non-monetary returns to education. Using a comprehensive data set on mortality and compulsory schooling reforms implemented across Europe between 1903 and 1976, we investigate how these reforms - covering many different countries and time periods - affect mortality for men and women. We find that compulsory schooling reforms have reduced mortality for men both in the short- and long-run. In contrast, we find no effect for women. We further document that there is substantial heterogeneity of the mortality benefits across countries and time periods. Effects seem to be larger for reforms implemented earlier in the twentieth century.

We further show that compulsory schooling reforms increased educational attainment by around 4 months for both men and women. Hence, the gender differences in differences cannot be explained by differential rates of compliance with the new schooling requirements. Gender-specific occupational choices and associated exposure to health hazards might provide an alternative explanation. For instance, male compliers, traditionally overrepresented in blue-collar jobs, might be more likely to find a white-collar 
job after the compulsory schooling reform and thus be less exposed to hazardous working conditions. Understanding these gender differences might be a promising avenue to shed more light on the possible pathways from education to health. 


\section{References}

Albouy, V. and L. Lequien (2009). "Does compulsory schooling lower mortality,” Journal of Health Economics, 28, 155-68.

Angrist, J.D., and A.B. Krueger (1992), "The effect of age at school entry on educational attainment: An application of instrumental variables with moments from two samples." Journal of the American Statistical Association, 87(418), 328-36.

Arendt, J. N. (2005), "Does education cause better health? A panel data analysis using school reforms for identification." Economics of Education Review, 24(2):149-160.

Ashenfelter, O., C. Harmon and H. Oosterbeek (1999), “A review of estimates of the schooling/earnings relationship, with tests for publication bias," Labour Economics, 6(4), 453-470.

Bingley, P., V.M. Jensen and A.Q. Romani (2009), "Intergenerational transmission of human capital: Reform-based evidence from Denmark,” Working paper.

Black, D., J. Galdo, and J.A. Smith (2007), "Evaluating the bias of the regression discontinuity design using experimental data." University of Chicago, Working paper.

Borenstein M., L. Hedges, J. Higgins and H. Rothstein (2009), Introduction to meta-analysis. Chichester, West Sussex, UK: John Wiley and Sons.

Brandolini, A. and P. Cipollone (2002), "Return to Education in Italy 19921997.” Bank of Italy, Research Department.Working Paper, September.

Brunello, G., M. Fort and G. Weber (2009), "Changes in compulsory schooling, education and the distribution of wages in Europe", Economic Journal, 119 (March), 516-539.

Card, D. and A. Krueger (1995), “Time-Series Minimum-wage studies: a meta-analysis," American Economic Review Papers and Proceedings, 85(2), 238-43.

Chetty, R., A. Guren, D. Manoli, and A. Weber (2012), "Does indivisible labor explain the difference between micro and macro elasticities? A meta-analysis of extensive margin elasticities, NBER Macroeconomics Annual, forthcoming.

Clark, D. and H. Royer (2010). "The effect of education on adult health and mortality: Evidence from Britain,” NBER working paper 16013.

Cutler, D.M. and A. Lleras-Muney (2010), "Understanding differences in health behavior by education," Journal of Health Economics, 29, $1-28$. 
European Commission (2011), "Eurydice - Network on education systems and policies in Europe," available online at http://eacea.ec.europa.eu/education/eurydice.

Fort, M. (2006). "Educational reforms across Europe: A toolbox for empirical research," University of Padova working paper.

Fort, M. N. Schneeweis and R. Winter-Ebmer (2011), "More Schooling, More Children: Compulsory Schooling Reforms and Fertility in Europe,” IZA Working Paper No. 6015.

Garrouste, C. (2010), "100 years of educational reforms in Europe: A contextual database,” European Commission Joint Research Center, Luxembourg: Publications, Office of the European Union.

Grenet, J. (2011), "Is it enough to increase compulsory education to raise earnings? Evidence from French and British compulsory schooling laws,” mimeo, Paris School of Economics.

Grossman, M. (2006), “Education and non-market outcomes.” In: Handbook of the Economics of Education, edited by Eric Hanushek and Finis Welch, Elsevier Science.

Hansen, J. and R. Wahlberg (2005), "Endogenous schooling and the distribution of the gender wage gap.” Empirical Economics, 30, 122.

Harmon, C. and I. Walker (1995). "Estimates of the economic return to schooling for the United Kingdom,” American Economic Review, 85(5), 1278-1286.

Haveman, R.H. \& Wolfe. B.L. (1984), "Schooling and economic well-being: The role of nonmarket effects," Journal of Human Resources, 19(3), 377-407.

Higgins, J.P.T., S.G. Thompson, J.J. Deeks and D.G.Altman (2003), "Measuring inconsistency in meta-analyses," British Medical Journal, 327(7414),

Holmlund, H. (2007), "A researcher's guide to the Swedish compulsory school reform," Swedish Institute for Social Research (SOFI), working paper 9/2007.

Human Mortality Database (2011), University of California, Berkeley (USA), and Max Planck Institute for Demographic Research (Germany). Available at www.mortality.org or www.humanmortality.de (data downloaded on March 23, 2010).

Imbens and Lemieux (2008), "Regression discontinuity designs: A guide to practice,” Journalof Econometrics, 142(2), 615-635.

Inoue, A., and G. Solon (2010), "Two-sample instrumental variables estimators.” Review of Economics and Statistics, 92(3), 557-61. 
Kemptner, D., H. Jürges and S. Reinhold (2011), “Changes in compulsory schooling and the causal effect of education on health: Evidence from Germany,” Journal of Health Economics, 30(2), 340-354.

Lee, D.S., and T. Lemieux (2010), "Regression discontinuity designs in economics.” Journal of Economic Literature, 48(2), 281-355.

Levin, J. and E.J.S. Plug (1999), "Instrumenting education and the returns to schooling in the Netherlands," Labour Economics, 6, 521-534.

Lleras-Muney, A. (2005), "The relationship between education and adult mortality in the United States," Review of Economic Studies, 72(1), 189-221.

Mazumder, B. (2008), "Does education improve health? A reexamination of the evidence from compulsory schooling laws." Economic Perspectives, 32(2), 2-16.

Meghir, C. and M. Palme (2005), "Educational reform, ability, and family background," American Economic Review, 95(1), 414-426.

Micklewright, J., M. Pearson and S. Smith (1989), "Has Britain an early school leaving problem?” Fiscal Studies, 10(1), 1 - 16.

Moravec, P. (1996), “Austria: Development of education in Austria 19941996.” Technical report, Federal Ministry of Education, Science and Culture, Vienna.

Murtin, F. and M. Viarengo (2011), "The expansion and convergence of compulsory schooling in Western Europe, 1950-2000.” Economica, 78(311), 501-522.

Oreopoulos, P. (2006), "Estimating average and local average treatment effects when compulsory schooling laws really matter." American Economic Review, 96(1), 152-175.

Oreopolous, P. and K. Salvanes (2011), "Priceless: The nonpecuniary benefits of schooling,” Journal of Economic Perspectives, 25(1), 159-184.

Tajalli, E., S. Polzer, and G. Czipke (2001). "Development of education in Austria 1997-2000.” Technical report, Federal Ministry of Education, Science and Culture, Vienna.

van Kippersluis, H., O. O’Donnell, and E. van Doorslaer (2011). "Long-run returns to education: Does schooling lead to an extended old age?” Journal of Human Resources, 46(4), 695-721.

Wielemans, W. (1991), "Comprehensive education in Belgium: A broken lever? European Journal of Education, 26(2), 167-178.

Wilmoth, J.R., K. Andreev, D. Jdanov, and D.A. Glei (2007), "Methods protocol for the Human Mortality Database, Working paper, Version 5 (last revised May 31, 2007). Available online at http://www.mortality.org/Public/Docs /MethodsProtocol.pdf. 


\section{Appendix: Reforms in Compulsory Schooling Laws}

We base our analysis on 19 reforms of compulsory schooling in 12 European countries or regions: Austria, Belgium, Denmark, England and Wales, France, Ireland, Italy, the Netherlands, Northern Ireland, Portugal, Scotland, Spain and Sweden.

We include all reforms implemented between 1900 and 1980 for which we could identify the exact year of the reform's implementation and the birth year of the first cohort affected by the reform. We drop all reforms that were implemented since 1980 because we cannot analyze their effects on longer-run mortality (like 30-, 40- or 50-years mortality rates from age 18 onward) for those reforms. In addition, we exclude reforms that were only partially implemented (like the Portuguese reform in 1973) or were implemented at the sub-national level (for example, compulsory schooling reforms in Germany were implemented by individual states between 1947 and 1969; similarly, the schooling reform in Finland was implemented between 1972 and 1977). The main reason is that our mortality data is only available at the cohort level but does not contain any information on place of birth or place of residence while in school. Finally, we also exclude reforms that reduced the number of compulsory schooling years (like the reforms in the Netherlands in 1947) or reforms that were implemented during the two World Wars to avoid confounding effects from war-related disruptions.

To obtain the necessary information for each reform (like the year of implementation, the number of additional years of compulsory schooling and the birth year of the first cohort affected), we start out with the comprehensive survey of European educational systems and major schooling reforms by Fort (2006). We extended the time frame to reforms prior to World War I and cross-checked the information for each reform using multiple sources and by contacting experts in the respective countries. As a result, our set of compulsory schooling reforms and coding of the variables differ somewhat from Fort (2006) and Brunello, Fort and Weber (2009). Table 1 shows the relevant information for each reform we use in our estimation. Here, we provide a brief summary of each reform in chronological order and highlight how we coded our reform indicator.

\section{Denmark (1903 and 1971):}

Seven years of compulsory education was introduced in 1814 and a system of municipal education authorities was built up. In 1903, the municipal town schools and grammar schools were coordinated by the Act on Secondary Schools. According to this act, a four-year Middle School was introduced both in the grammar schools and in the municipal town schools. After a test in the 5th form, pupils could be admitted to the Middle School. After the Middle School examination, pupils could then leave school, continue one more year in the realeksamen class and prepare themselves for the lower secondary school 
leaving examination (the realeksamen) or apply for admission to the grammar school's three years of general upper secondary education. The extent to which this had an impact on mean education is however dubious, since most children already obtained 9 years of schooling.

In 1971, compulsory education was extended from seven to nine years which was implemented in 1972. Furthermore, a new act on the Folkeskole was adopted in 1975. The aim of the new act was to create equal opportunities for all pupils and the result was the introduction of nine years of comprehensive primary and lower secondary education - combined with an additional optional 10th year and an optional pre-school class.

School starts at the age of 7 (the school year ran from April to April; since 1958, it ran from August to August). There is some disagreement in the literature on the timing of the expansion of mandatory schooling. Brunello et al. (2009) argue that the expansion took place in 1971 and use the birth cohort 1957 as the first affected cohort. Arendt (2005), on the other hand, has coded the expansion as taking place in 1975 with the introduction of the Folkeskole. Consequently, the first affected cohort would then be born in 1961. Here, we follow Brunello et al. (2009) but present the reduced form results using the alternative 1975/1961 coding in the robustness section.

Sources: Arendt (2005); Bingley et al. (2009); Brunello, Fort and Weber (2009) European Commission (2011).

\section{Belgium (1919):}

The government introduced compulsory schooling from age 6 to age 12 for the first time with the act of May 19, 1914. The act also stipulated that the upper age limit would be further increased to 13 and then to 14 years of age. The law was only implemented after the end of World War I; hence, since 1919 the school-leaving age was set to 14 years of age.

Sources: European Commission (2011), Fort (2006), Wielemans (1991).

\section{Netherlands (1928, 1950 and 1973):}

The first legislation making education compulsory was passed in 1900. It prescribed 6 years of compulsory education (between the ages of 6 and 12). The Act was repeatedly amended in 1921 (from 6 to 7 years), in 1924 (from 7 to 6 years), in 1928 (from 6 to 7 years). In 1950, compulsory schooling was further increased from 7 to 9 years.

The Compulsory Education Act 1975 extended compulsory schooling years requiring children to attend school full-time between the ages of 6 and 16 . This meant that also 15-year olds had to follow full-time education. The increase in the compulsory school leaving age was accompanied by an extension of three-year lower vocational programs to four years. The reform therefore incorporated that all schools of lower vocational education should implement a second general year. In this year the curriculum ought to include at least 20 weekly lessons in general training. The implementation of the extension of lower vocational education started in 1973. Since August 1, 1973 
all lower vocational programs had a length of four years. Therefore, students born on or after August 1, 1959 therefore had to follow ten years of full-time education. This is also the first cohort of students to encounter a complete four-year lower vocational education regime.

In 1985 the lower age limit for compulsory schooling was lowered from six to five. Children must now attend school full time from the age of five for at least 12 full school years and, in any event, until the end of the school year in which they turn 16.

Sources: European Commission (2011); Levin and Plug (1999); Murtin and Viarengo (2011); Osterbeek and Webbink (2004).

\section{France (1936 and 1967):}

The Zay reform increased the minimal school leaving age from 13 to 14 years of age raising the number of compulsory schooling years from 7 to 8 . The reform thus affected all children that were 13 years of age suggesting that the first cohort potentially affected by the reform was born in 1923 .

1967, which extended compulsory education by two more years. The reform affected all individuals that were 14 in 1967; hence, the first affected cohort is born in 1953.

Sources: Albouy and Lequien (2009); Grenet (2011) for the second reform.

\section{England and Wales (1947 and 1973) and Scotland (1946 and 1976):}

The Education Act in 1944 known as the Butler Act established the basic legal framework governing decisions about school-leaving. The compulsory schooling laws specify the maximum age by which children must start school (which is 5) and the minimum age at which children can leave school in England and Wales as well as Scotland. A Ministerial order later in 1944 specified that from April 1, 1947 onwards it made education up to the age of 15 compulsory and provided for the school-leaving age to be raised at a later date to 16. The increase to 16 years was implemented in England and Wales in 1973. As a consequence, the 1947 reform raised the number of compulsory schooling years from 8 to 9 and affected all cohorts born after April 1933. The reform in 1973 change raised it to 10 years and affected all cohorts born September 1957 or later.

Sources: Clark and Royer (2010); Harmon and Walker (1995); Micklewright et al. (1989); Murtin and Viarengo (2011).

Northern Ireland (1957 and 1972):

The 1947 Education Act in Northern Ireland was closely modeled on Britain's Butler Act. It raised the minimum school leaving age from 14 to 15 . However, in Northern Ireland political opposition delayed the implementation of the law until 1957. Therefore, the first cohort affected by the reform is born in 1943 . The reform in 1972 was again modeled after the reform in England and Wales. Sources: Eurydice (2011); Oreopoulos (2006). 


\section{Sweden (1962):}

In 1962 the Riksdag decided to introduce the new 9 years compulsory school (grundskolan). The law was preceded by extensive experimentation, where changes in compulsory schooling years were implemented stepwise at the municipal level between 1949 and 1962. In 1961, about 25 percent of the municipalities were assigned to the new system. The experimentation followed a proposal by a parliamentary committee in 1948 to replace the compulsory 7 school years and junior secondary school with a nine-year compulsory comprehensive school. The national implementation took place in 1962 but the cohort from which the new school system was implemented varied between municipalities. Some implemented the new system for all cohorts up to those who were in fifth grade at the time. Others, however, implemented it starting only with the cohort of pupils who were in first grade in 1962. Here, we follow Brunello, Fort and Weber (2009) and define all the individuals born after 1950 as potentially affected by the reform.

Sources: Brunello, Fort and Weber (2009); Eurydice (2011); Holmlund (2007); Meghir and Palme (2005).

Italy (1963):

The first relevant reform (the No. 1859 act, December 31, 1962) prescribes the unification of the previous scuola media and scuola di avviamento professionale in a single compulsory scuola media. Compulsory schooling was raised from 5 to 8 years such that children remained in school until age 15. The reform was passed at the end of 1962 and was implemented in 1963. Hence, the reform affected all individuals born in 1951 or later. We thus code the first affected cohort as 1949 (which had to stay in school one year longer). Source: Brandolini and Cipollone (2002).

\section{Austria (1966):}

In 1962, the parliament amended the constitution to reorganize the responsibilities in education and school administration (Schulverfassungsnovelle or School Act Amendment of 1962). Several federal education acts followed in 1962, among them the Schulpflichtgesetz which was implemented in 1966. The reform increased compulsory schooling from 8 to 9 years. Since school age starts at age 6 , the timing suggests that the first cohort affected was born in 1953. However, individuals born in 1952 who might have already left school when the reform was introduced were required to go back to school and complete the additional year.

Sources: Bundesgesetzblatt Nr. 241/1962, 8. August 1962; Moravec (1996); Murtin and Viarengo (2011).

\section{Spain (1970):}

Compulsory schooling was introduced with the Public Instruction Act (Ley Moyano) in 1857 requiring children to attend school from age 6 to 14 . Elementary education was free and compulsory from age 6 to 9. Enforcement 
however, seems to have been poor (esp. in agricultural areas) and the number of places in schools was typically smaller than the number of school-age children.

A basic reform of the highly fragmented Spanish education system occurred with the Ley General de Educación y Financiamiento de la Reforma Educativa (General Act on Education and Financing of Educational Reform).in 1970. The new General Education System introduced the common school (educacion general básica) which offered 8 years of schooling (the school year runs from mid-September to the end of June). Schooling from age 6 to 14 became compulsory and free. The law affected all children that were age 13 in 1970 - hence, the first affected cohort is born 1957.

Sources: European Commission (2011), McNair (1981); Pons and Gonzalo (2002).

\section{Ireland (1972):}

The content of the curriculum between 1922 and 1971 was based on the reality that schooling would cease for many children at age 14. In 1967, new policy departures in relation to both first and second level were to transform the role of primary schools in the educational system. Post-primary education was to be made available to all children without payment of fees. Transfer from primary to post-primary education occurred at age 12 or more and compulsory education was extended to age 15 by 1972 .

Sources: European Commission (2011), Murtin and Viarengo (2009). 
Table 1: Compulsory Schooling Reforms in Europe

\begin{tabular}{lcccccc}
\hline \hline & $\begin{array}{c}\text { Year reform } \\
\text { was }\end{array}$ & $\begin{array}{c}\text { First } \\
\text { cohort } \\
\text { implemented } \\
\text { fffected }\end{array}$ & $\begin{array}{c}\text { Change in } \\
\text { minimum } \\
\text { schooling } \\
\text { level }\end{array}$ & $\begin{array}{c}\text { Change in } \\
\text { the } \\
\text { number of } \\
\text { years }\end{array}$ & $\begin{array}{c}\text { Male 20-year } \\
\text { mortality for } \\
\text { first cohort } \\
\text { affected }\end{array}$ & $\begin{array}{c}\text { Female 20- } \\
\text { year mortality } \\
\text { for first cohort } \\
\text { affected }\end{array}$ \\
\hline \hline & & & & & & \\
Denmark & 1903 & 1890 & 7 to 9 & 2 & 0.083 & 0.085 \\
Belgium & 1919 & 1910 & 3 to 8 & 5 & 0.085 & 0.063 \\
Netherlands & 1928 & 1917 & 6 to 7 & 1 & 0.052 & 0.033 \\
France & 1937 & 1923 & 7 to 8 & 1 & 0.095 & 0.054 \\
Scotland & 1946 & 1932 & 8 to 9 & 1 & 0.028 & 0.019 \\
England and Wales & 1947 & 1933 & 8 to 9 & 1 & 0.022 & 0.014 \\
Netherlands & 1950 & 1938 & 7 to 9 & 2 & 0.020 & 0.011 \\
Northern Ireland & 1957 & 1943 & 8 to 9 & 1 & 0.028 & 0.013 \\
Sweden & 1962 & 1950 & 8 to 9 & 1 & 0.024 & 0.011 \\
Italy & 1963 & 1949 & 5 to 8 & 3 & 0.022 & 0.011 \\
Austria & 1966 & 1953 & 8 to 9 & 1 & 0.034 & 0.015 \\
France & 1967 & 1953 & 8 to 10 & 2 & 0.035 & 0.014 \\
Spain & 1970 & 1957 & 6 to 8 & 2 & 0.029 & 0.010 \\
Ireland & 1972 & 1958 & 8 to 9 & 1 & 0.022 & 0.009 \\
Northern Ireland & 1972 & 1958 & 9 to 10 & 1 & 0.028 & 0.011 \\
Denmark & 1971 & 1957 & 7 to 9 & 2 & 0.028 & 0.012 \\
England and Wales & 1973 & 1958 & 9 to 10 & 1 & 0.019 & 0.009 \\
Netherlands & 1973 & 1959 & 9 to 10 & 1 & 0.019 & 0.009 \\
Scotland & 1976 & 1958 & 9 to 10 & 1 & 0.023 & 0.011 \\
& & & & & & \\
\hline
\end{tabular}

Sources: see the data appendix for a description of each compulsory schooling reform. Mortality rates in the last two columns are based on data from the Human Mortality Database (2011). 
Table 2: Effect of Compulsory Schooling Reforms on Male Mortality

\begin{tabular}{|c|c|c|c|c|c|c|c|c|c|}
\hline Country & Year & OR (20-year) & $95 \%-\mathrm{Cl}$ & OR (30-year) & $95 \%-\mathrm{Cl}$ & OR (40-year) & $95 \%-\mathrm{Cl}$ & OR (50-year) & $95 \%-\mathrm{Cl}$ \\
\hline Denmark & 1903 & 0.982 & $(0.905,1.065)$ & 0.991 & $(0.949,1.035)$ & 1.007 & $(0.957,1.060)$ & 0.992 & $(0.956,1.029)$ \\
\hline Belgium & 1919 & 0.903 & $(0.848,0.961)$ & 0.947 & $(0.913,0.983)$ & 0.956 & $(0.933,0.980)$ & 0.959 & $(0.939,0.981)$ \\
\hline Netherlands & 1928 & 0.949 & $(0.824,1.094)$ & 0.950 & $(0.880,1.024)$ & 0.973 & $(0.933,1.015)$ & 0.992 & $(0.965,1.020)$ \\
\hline France & 1937 & 1.348 & $(1.048,1.734)$ & 1.216 & $(1.023,1.444)$ & 1.129 & $(1.015,1.255)$ & 1.081 & $(1.002,1.166)$ \\
\hline Scotland & 1946 & 1.016 & $(0.942,1.096)$ & 0.957 & $(0.907,1.009)$ & 0.974 & $(0.947,1.003)$ & 1.016 & $(0.990,1.042)$ \\
\hline England and Wales & 1947 & 0.935 & $(0.783,1.116)$ & 0.943 & $(0.867,1.025)$ & 0.969 & $(0.924,1.015)$ & 1.013 & $(0.984,1.043)$ \\
\hline Netherlands & 1950 & 0.981 & $(0.913,1.054)$ & 0.958 & $(0.919,0.999)$ & 0.938 & $(0.900,0.978)$ & & \\
\hline Northern Ireland & 1957 & 0.926 & $(0.871,0.983)$ & 1.047 & $(0.946,1.158)$ & 1.037 & $(0.920,1.170)$ & & \\
\hline Sweden & 1962 & 0.983 & $(0.919,1.052)$ & 0.973 & $(0.932,1.015)$ & & & & \\
\hline Italy & 1963 & 1.025 & $(0.969,1.085)$ & 1.016 & $(0.957,1.078)$ & & & & \\
\hline Austria & 1966 & 0.935 & $(0.876,0.998)$ & 0.940 & $(0.875,1.010)$ & & & & \\
\hline France & 1967 & 0.951 & $(0.927,0.976)$ & 0.979 & $(0.939,1.021)$ & & & & \\
\hline Spain & 1970 & 0.984 & $(0.939,1.032)$ & 0.979 & $(0.934,1.025)$ & & & & \\
\hline Ireland & 1972 & 0.973 & $(0.909,1.042)$ & & & & & & \\
\hline Northern Ireland & 1972 & 0.943 & $(0.864,1.029)$ & & & & & & \\
\hline England and Wales & 1973 & 0.984 & $(0.971,0.998)$ & & & & & & \\
\hline Netherlands & 1973 & 1.027 & $(0.959,1.100)$ & & & & & & \\
\hline Denmark & 1971 & 1.064 & $(0.920,1.229)$ & 1.003 & $(0.887,1.134)$ & & & & \\
\hline Scotland & 1976 & 0.938 & $(0.885,0.994)$ & & & & & & \\
\hline Pooled Estimates & & 0.972 & $(0.954,0.990)$ & 0.972 & $(0.957,0.988)$ & 0.974 & $(0.952,0.997)$ & 0.999 & $(0.999,1.024)$ \\
\hline
\end{tabular}


Table 3: Effect of Compulsory Schooling Reforms on Female Mortality

\begin{tabular}{|c|c|c|c|c|c|c|c|c|c|}
\hline Country & Year & OR (20-year) & $95 \%-\mathrm{Cl}$ & OR (30-year) & $95 \%-\mathrm{Cl}$ & OR (40-year) & $95 \%-\mathrm{Cl}$ & OR (50-year) & $95 \%-\mathrm{Cl}$ \\
\hline Denmark & 1903 & 1.05 & $(0.995,1.108)$ & 1.017 & $(0.974,1.063)$ & 0.996 & $(0.969,1.025)$ & 1.030 & $(1.005,1.056)$ \\
\hline Belgium & 1919 & 1.005 & $(0.943,1.072)$ & 1.026 & $(0.975,1.079)$ & 1.040 & $(0.997,1.084)$ & 1.000 & $(0.978,1.023)$ \\
\hline Netherlands & 1928 & 0.891 & $(0.841,0.945)$ & 0.941 & $(0.900,0.983)$ & 0.947 & $(0.921,0.974)$ & 0.987 & $(0.972,1.002)$ \\
\hline France & 1937 & 1.082 & $(0.954,1.226)$ & 1.041 & $(0.955,1.134)$ & 1.016 & $(0.956,1.081)$ & 1.005 & $(0.965,1.047)$ \\
\hline Scotland & 1946 & 0.999 & $(0.959,1.040)$ & 1.033 & $(0.994,1.074)$ & 0.986 & $(0.943,1.031)$ & 0.985 & $(0.955,1.016)$ \\
\hline England and Wales & 1947 & 1.002 & $(0.974,1.031)$ & 1.006 & $(0.971,1.042)$ & 1.001 & $(0.969,1.034)$ & 1.032 & $(1.017,1.047)$ \\
\hline Netherlands & 1950 & 0.935 & $(0.839,1.041)$ & 0.964 & $(0.925,1.005)$ & 0.989 & $(0.934,1.047)$ & & \\
\hline Northern Ireland & 1957 & 0.957 & $(0.799,1.146)$ & 0.966 & $(0.918,1.016)$ & 0.937 & $(0.851,1.032)$ & & \\
\hline Sweden & 1962 & 1.115 & $(0.981,1.267)$ & 1.014 & $(0.948,1.086)$ & & & & \\
\hline Italy & 1963 & 0.983 & $(0.931,1.038)$ & 0.998 & $(0.958,1.041)$ & & & & \\
\hline Austria & 1966 & 1.026 & $(0.953,1.104)$ & 1.001 & $(0.953,1.052)$ & & & & \\
\hline France & 1967 & 0.967 & $(0.918,1.018)$ & 0.959 & $(0.925,0.994)$ & & & & \\
\hline Spain & 1970 & 1.018 & $(0.934,1.108)$ & 1.023 & $(0.984,1.064)$ & & & & \\
\hline Ireland & 1972 & 0.934 & $(0.845,1.032)$ & & & & & & \\
\hline Northern Ireland & 1972 & 0.878 & $(0.791,0.975)$ & & & & & & \\
\hline England Wales & 1973 & 0.994 & $(0.956,1.034)$ & & & & & & \\
\hline Netherlands & 1973 & 0.995 & $(0.940,1.054)$ & & & & & & \\
\hline Denmark & 1971 & 0.968 & $(0.801,1.170)$ & 1.044 & $(0.927,1.177)$ & & & & \\
\hline Scotland & 1976 & 0.986 & $(0.912,1.065)$ & & & & & & \\
\hline Pooled Estimates & & 0.988 & $(0.968,1.009)$ & 0.997 & $(0.980,1.014)$ & 0.991 & $(0.968,1.014)$ & 1.007 & $(0.988,1.027)$ \\
\hline
\end{tabular}

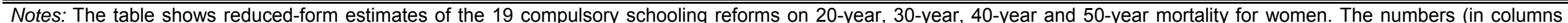

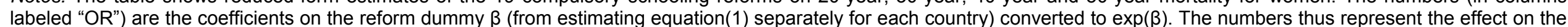

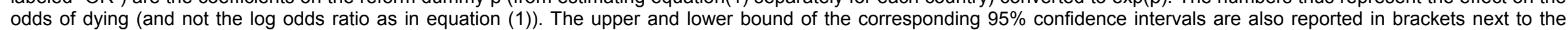

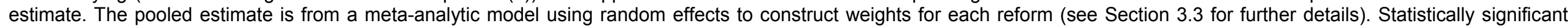
effects are marked in bold. 
Table 4: Effect of Compulsory Schooling Reforms on Years of Schooling

\begin{tabular}{|c|c|c|c|c|c|c|c|c|}
\hline \multirow[b]{2}{*}{ Country } & \multirow[b]{2}{*}{$\begin{array}{c}\text { Reform } \\
\text { Year }\end{array}$} & \multirow{2}{*}{$\begin{array}{l}\text { Change in } \\
\text { compulsory } \\
\text { schooling }\end{array}$} & \multirow[b]{2}{*}{ Gender } & \multicolumn{2}{|c|}{ Our estimates } & \multicolumn{3}{|c|}{ Estimates from the literature } \\
\hline & & & & $\begin{array}{l}\text { First stage } \\
\text { for } 2 S L S\end{array}$ & $\begin{array}{c}\text { Standard } \\
\text { error }\end{array}$ & First stage & $\begin{array}{l}\text { Standard } \\
\text { error }\end{array}$ & Source \\
\hline Netherlands & 1928 & 6 to 7 & Men & 1.745 & (3.480) & 0.669 & (0.109) & Kippersluis et al. (2011) \\
\hline Netherlands & 1928 & 6 to 7 & Women & 1.173 & $(0.707)$ & no effect & not reported & Kippersluis et al. (2011) \\
\hline France & 1937 & 7 to 8 & All & & & 0.110 & $(0.064)$ & Albouy and Lequien (2009) \\
\hline France & 1937 & 7 to 8 & Men & -1.788 & $(1.642)$ & & & \\
\hline France & 1937 & 7 to 8 & Women & 0.161 & $(0.880)$ & & & \\
\hline England and Wales & 1947 & 8 to 9 & Men & 0.421 & $(0.645)$ & 0.420 & $(0.062)$ & Clark and Royer (2010) \\
\hline England and Wales & 1947 & 8 to 9 & Women & 0.425 & $(0.460)$ & 0.527 & $(0.054)$ & Clark and Royer (2010) \\
\hline Great Britain & 1947 & 8 to 9 & All & & & 0.436 & $(0.071)$ & Oreopoulos (2006) \\
\hline Netherlands & 1950 & 7 to 9 & Men & -0.617 & (0.795) & -0.399 & $(0.564)$ & Levin and Plug (1999) \\
\hline Netherlands & 1950 & 7 to 9 & Women & 0.342 & $(0.634)$ & & & \\
\hline Northern Ireland & 1957 & 8 to 9 & All & & & 0.391 & $(0.073)$ & Oreopoulos (2006) \\
\hline Sweden & 1962 & 8 to 9 & All & & & 0.298 & $(0.075)$ & Meghir and Palme (2005) \\
\hline Sweden & 1962 & 8 to 9 & Men & -0.014 & (0.539) & 0.252 & $(0.081)$ & Meghir and Palme (2005) \\
\hline Sweden & 1962 & 8 to 9 & Women & -0.325 & $(0.476)$ & 0.339 & $(0.105)$ & Meghir and Palme (2005) \\
\hline Italy & 1963 & 5 to 8 & Men & 0.581 & $(0.854)$ & & & \\
\hline Italy & 1963 & 5 to 8 & Women & -0.095 & $(0.710)$ & 0.190 & $(0.035)$ & Brandolini and Cippolone (2011) \\
\hline Austria & 1966 & 8 to 9 & Men & 1.551 & $(0.769)$ & & & \\
\hline Austria & 1966 & 8 to 9 & Women & 0.943 & $(0.615)$ & & & \\
\hline France & 1967 & 8 to 10 & All & & & 0.280 & $(0.063)$ & Albouy and Lequien (2009) \\
\hline France & 1967 & 8 to 10 & Men & 0.348 & $(0.692)$ & 0.263 & $(0.025)$ & Grenet (2011) \\
\hline France & 1967 & 8 to 10 & Women & 1.271 & $(0.617)$ & 0.274 & $(0.035)$ & Grenet (2011) \\
\hline Spain & 1970 & 6 to 8 & Men & 1.292 & $(0.843)$ & 0.720 & $(0.274)$ & Pons and Gonzalo (2002) \\
\hline Spain & 1970 & 6 to 8 & Women & 0.824 & $(0.821)$ & & & \\
\hline Denmark & 1971 & 7 to 9 & Men & 0.450 & (0.681) & 0.262 & $(0.285)$ & Arendt (2005) \\
\hline Denmark & 1971 & 7 to 9 & Women & -0.161 & $(0.667)$ & 0.166 & $(0.302)$ & Arendt (2005) \\
\hline Ireland & 1972 & 8 to 9 & Men & 0.069 & $(0.597)$ & & & \\
\hline Ireland & 1972 & 8 to 9 & Women & 0.477 & $(0.520)$ & & & \\
\hline England and Wales & 1973 & 9 to 10 & Men & 1.078 & $(0.599)$ & 0.267 & $(0.028)$ & Grenet (2011) \\
\hline England and Wales & 1973 & 9 to 10 & Men & 1.078 & (0.599) & 0.318 & $(0.049)$ & Clark and Royer (2010) \\
\hline England and Wales & 1973 & 9 to 10 & Women & 0.427 & $(0.473)$ & 0.310 & $(0.022)$ & Grenet (2011) \\
\hline England and Wales & 1973 & 9 to 10 & Women & 0.427 & $(0.473)$ & 0.252 & $(0.050)$ & Clark and Royer (2010) \\
\hline Netherlands & 1973 & 9 to 10 & Men & 0.324 & $(0.830)$ & & & \\
\hline Netherlands & 1973 & 9 to 10 & Women & 1.173 & $(0.707)$ & & & \\
\hline \multirow[t]{2}{*}{ Pooled Estimates } & & & Men & 0.42 & $(0.200)$ & & & \\
\hline & & & Women & 0.35 & $(0.161)$ & & & \\
\hline
\end{tabular}

Notes: The table shows the first-stage of compulsory schooling laws on education. The coefficients are from estimating equation (1) separately by country and gender where the dependent variable is years of schooling completed. The set of cohorts is restricted to 10 cohorts above and below the reform threshold. The right-hand side of the table shows first-stage estimates reported in the literature for each reform and the respective sources. 
Table 5: Effect of Compulsory Schooling Reforms on 30-Year Mortality (Two-Sample 2SLS and Reduced-form Estimates)

\begin{tabular}{|c|c|c|c|c|c|c|c|c|c|}
\hline \multirow{3}{*}{ Country } & \multirow{3}{*}{ Year } & \multicolumn{4}{|c|}{ Men } & \multicolumn{4}{|c|}{$\underline{\text { Women }}$} \\
\hline & & \multicolumn{2}{|c|}{ Two-Sample 2SLS } & \multicolumn{2}{|c|}{ Reduced-Form } & \multicolumn{2}{|c|}{ Two-Sample 2SLS } & \multicolumn{2}{|c|}{ Reduced-Form } \\
\hline & & OR (30-year) & $95 \%-\mathrm{Cl}$ & OR (30-year) & $95 \%-\mathrm{Cl}$ & OR (40-year) & $95 \%-\mathrm{Cl}$ & OR (50-year) & $95 \%-\mathrm{Cl}$ \\
\hline Netherlands & 1928 & 0.988 & $(0.949,1.029)$ & 0.950 & $(0.873,1.033)$ & 0.965 & $(0.883,1.055)$ & 0.941 & $(0.896,0.988)$ \\
\hline France & 1937 & & & & & 0.932 & $(0.741,1.172)$ & 1.041 & $(0.946,1.145)$ \\
\hline England and Wales & 1947 & 0.864 & $(0.599,1.246)$ & 0.943 & $(0.858,1.035)$ & 1.012 & $(0.959,1.067)$ & 1.006 & $(0.967,1.046)$ \\
\hline Netherlands & 1950 & & & & & 0.913 & $(0.746,1.119)$ & 0.964 & $(0.920,1.010)$ \\
\hline Austria & 1966 & 0.950 & $(0.926,0.975)$ & 0.940 & $(0.869,1.017)$ & 1.002 & $(0.920,1.092)$ & 1.001 & $(0.948,1.057)$ \\
\hline France & 1967 & 1.083 & $(0.786,1.491)$ & 0.979 & $(0.936,1.024)$ & 0.979 & $(0.958,1.000)$ & 0.959 & $(0.922,0.997)$ \\
\hline Pooled Estimates & & 0.961 & $(0.940,0.982)$ & 0.963 & $(0.931,0.995)$ & 0.982 & $(0.964,1.001)$ & 0.978 & $(0.953,1.003)$ \\
\hline
\end{tabular}

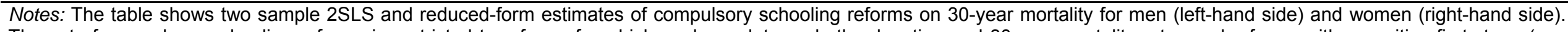

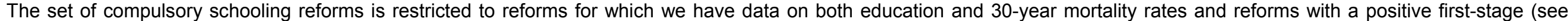

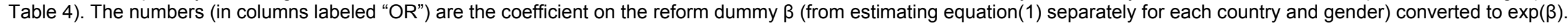

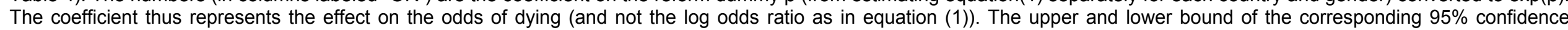

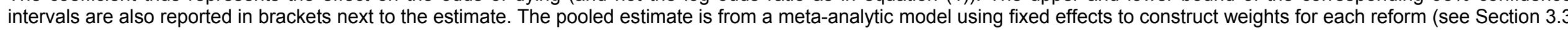
for further details). Statistically significant effects are marked in bold. 


\section{Figure 1: Reduced-form Estimates of Mandatory Schooling Reforms on 20-year Mortality Rates (Men)}

Country

(Year of Reform)

Estimate $(95 \% \mathrm{Cl})$

Denmark (1903)

Belgium (1919)

Netherlands (1928)

France (1937)

Scotland (1946)

EnglandWales (1947)

Netherlands (1950)

Northernlreland (1957)

Sweden (1962)

Italy (1963)

Austria (1966)

France (1967)

Spain (1970)

Denmark (1971)

Ireland (1972)

Northernlreland (1972)

EnglandWales (1973)

Netherlands (1973)

Scotland (1976)

Overall (I-squared $=44.8 \%, p=0.019$ )

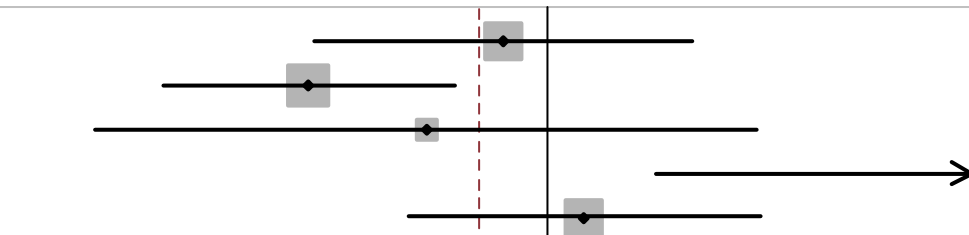

$0.982(0.905,1.065)$

$0.903(0.848,0.961)$

$0.949(0.824,1.094)$

$1.348(1.048,1.734)$

$1.016(0.942,1.096)$

$0.935(0.783,1.116)$

$0.981(0.913,1.054)$

$0.926(0.871,0.983)$

$0.983(0.919,1.052)$

$1.025(0.969,1.085)$

$0.935(0.876,0.998)$

$0.951(0.927,0.976)$

$0.984(0.939,1.032)$

$1.064(0.920,1.229)$

$0.973(0.909,1.042)$

$0.943(0.864,1.029)$

$0.984(0.971,0.998)$

$1.027(0.959,1.100)$

$0.938(0.885,0.994)$

$0.972(0.954,0.990)$

$8 \quad 85$

$\begin{array}{lll}1 & 9 & 1 \\ 85 & 9 & 95\end{array}$

$\begin{array}{llllll}5 & 1 & 1.05 & 1.1 & 1.15 & 1.2\end{array}$

Notes: The figure summarizes the reduced-form effects of 19 compulsory schooling reforms on the odds of men dying between the ages 18 and 38 (conditional on surviving to age 18). The point estimates (represented in the figure as a grey square) are constructed by estimating equation (1) and converting the resulting coefficient $\beta$ to $\exp (\beta)$. The corresponding confidence intervals are represented as a horizontal line. The size of each square indicates the weight of each reform in the pooled estimation (with larger squares indicating a higher weight). The ${ }^{2}$ statistic (in percentages) reflects the degree of heterogeneity of estimates. According to the $p$ value, we can reject the null that there is no heterogeneity across studies. The pooled estimate (using random reform effects to construct the weights) is shown as the dashed line. 


\section{Figure 2: Reduced-form Estimates of Mandatory Schooling Reforms on 20-year Mortality Rates (Women)}

Country

(Year of Reform)

Estimate $(95 \% \mathrm{Cl})$

Denmark (1903)

Belgium (1919)

Netherlands (1928)

France (1937)

Scotland (1946)

EnglandWales (1947)

Netherlands (1950)

Northernlreland (1957)

Sweden (1962)

Italy (1963)

Austria (1966)

France (1967)

Spain (1970)

Denmark (1971)

Ireland (1972)

NorthernIreland (1972)

EnglandWales (1973)

Netherlands (1973)

Scotland (1976)

Overall (I-squared $=45.5 \%, p=0.017)$

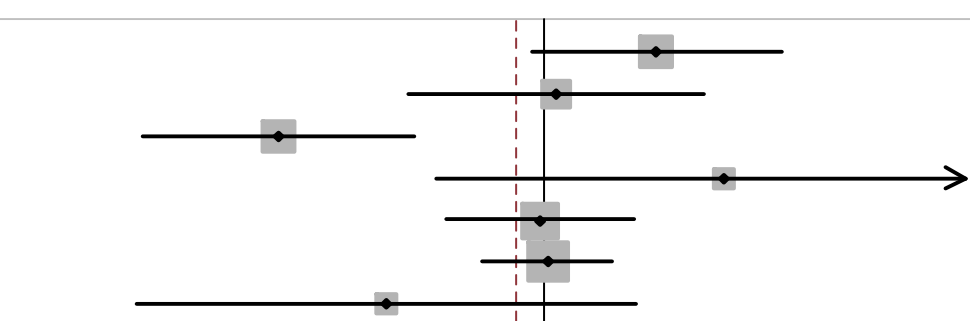

$1.050(0.995,1.108)$

$1.005(0.943,1.072)$

$0.891(0.841,0.945)$

$1.082(0.954,1.226)$

$0.999(0.959,1.040)$

$1.002(0.974,1.031)$

$0.935(0.839,1.041)$

$0.957(0.799,1.146)$

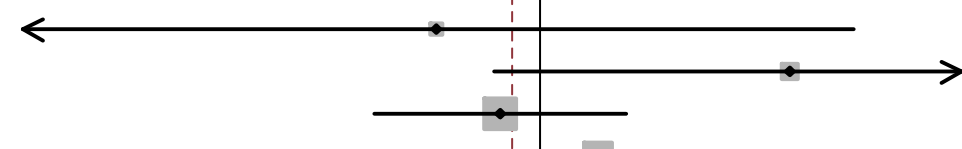

$1.115(0.981,1.267)$

$0.983(0.931,1.038)$

$1.026(0.953,1.104)$

$0.967(0.918,1.018)$

$1.018(0.934,1.108)$

$0.968(0.801,1.170)$

$0.934(0.845,1.032)$

$0.878(0.791,0.975)$

$0.994(0.956,1.034)$

$0.995(0.940,1.054)$

$0.986(0.912,1.065)$

$0.988(0.968,1.009)$

$.8 \quad .85$

$\begin{array}{lll} & & \\ 8 & 9 & .95\end{array}$

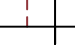

1.2

Notes: The figure summarizes the reduced-form effects of 19 compulsory schooling reforms on the odds of men dying between the ages 18 and 38 (conditional on surviving to age 18). The point estimates (represented in the figure as a grey square) are constructed by estimating equation (1) and converting the resulting coefficient $\beta$ to $\exp (\beta)$. The corresponding confidence intervals are represented as a horizontal line. The size of each square indicates the weight of each reform in the pooled estimation (with larger squares indicating a higher weight). The $\mathrm{I}^{2}$ statistic (in percentages) reflects the degree of heterogeneity of estimates. According to the $\mathrm{p}$ value, we can reject the null that there is no heterogeneity across studies. The pooled estimate (using random reform effects to construct the weights) is shown as the dashed line. 
Figure 3: 2SLS Estimates of the Effect of Education on 20-year Mortality Rates (Men)

\section{Country}

(Year of Reform)

Estimate $(95 \% \mathrm{Cl})$

Netherlands (1928)

EnglandWales (1947)

Austria (1966)

France (1967)

Spain (1970)

Denmark (1971)

Ireland (1972)

EnglandWales (1973)

Netherlands (1973)

Overall $($ I-squared $=0.0 \%, p=0.871)$

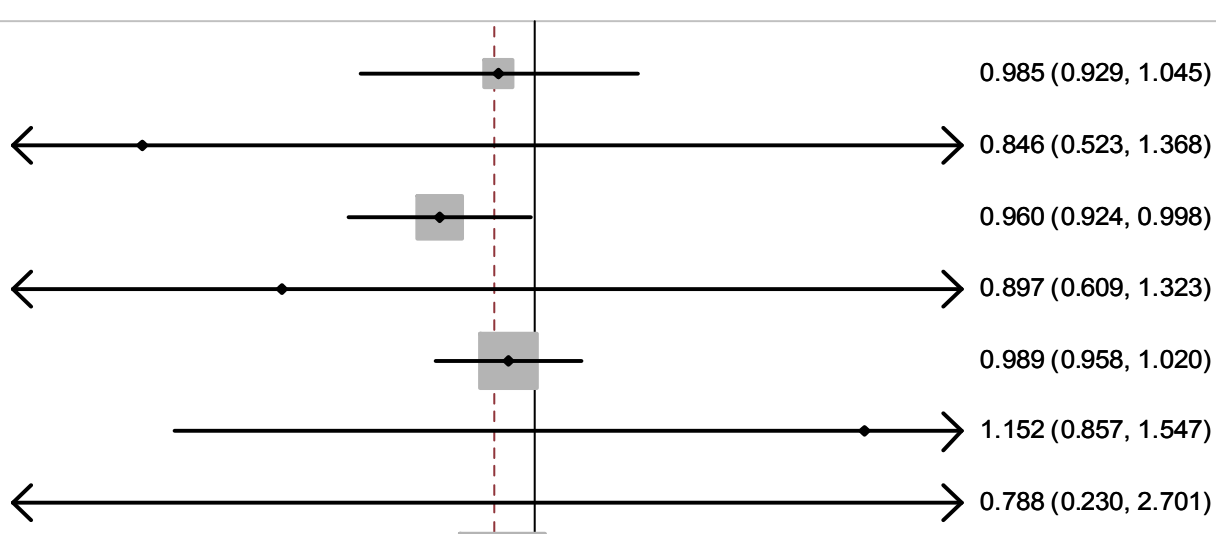

$0.986(0.966,1.007)$

$1.061(0.842,1.338)$

$0.983(0.968,0.998)$

.9

.95

Notes: The figure summarizes the two-sample 2SLS effects of 10 compulsory schooling reforms on the odds of men dying between the ages 18 and 38 (conditional on surviving to age 18). The point estimates (represented in the figure as a grey square) are constructed by estimating equation (1) and converting the resulting coefficient $\beta$ to $\exp (\beta)$. The corresponding confidence intervals are represented as a horizontal line. The size of each square indicates the weight of each reform in the pooled estimation (with larger squares indicating a higher weight). The $\mathrm{I}^{2}$ statistic (in percentages) reflects the degree of heterogeneity of estimates. According to the $p$ value, we cannot reject the null that there is no heterogeneity across studies. The pooled estimate (using fixed reform effects to construct the weights) is shown as the dashed line. 
Figure 4: 2SLS Estimates of the Effect of Education on 20-year Mortality Rates (Women)

Country

(Year of Reform)

Estimate $(95 \% \mathrm{Cl})$

Netherlands (1928)

France (1937)

EnglandWales (1947)

Netherlands (1950)

Austria (1966)

France (1967)

Spain (1970)

Ireland (1972)

EnglandWales (1973)

Netherlands (1973)

Overall (I-squared $=0.0 \%, p=0.637)$

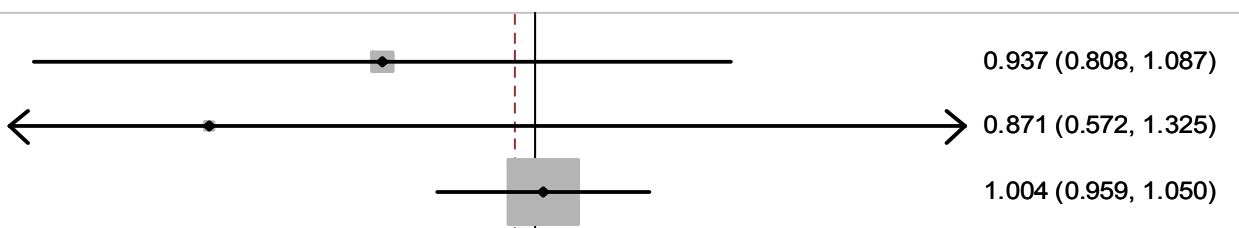

$1.004(0.959,1.050)$

$0.847(0.594,1.207)$

$1.029(0.966,1.096)$

$0.973(0.938,1.010)$

$1.019(0.950,1.093)$

$0.864(0.716,1.043)$

$0.986(0.900,1.080)$

$0.995(0.952,1.041)$

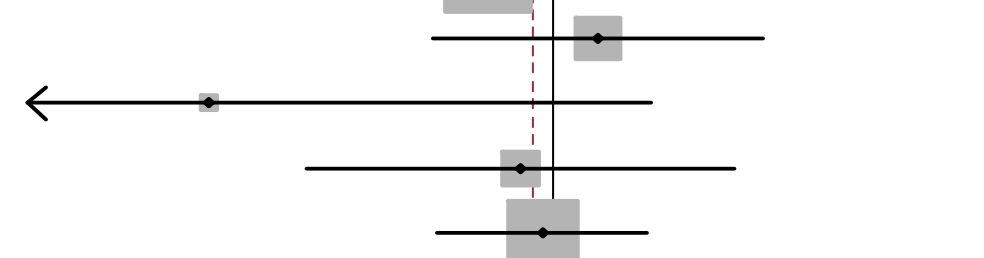

$0.991(0.971,1.012)$

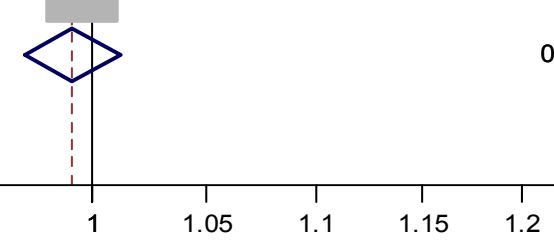

Notes: The figure summarizes the two-sample 2SLS effects of 10 compulsory schooling reforms on the odds of women dying between the ages 18 and 38 (conditional on surviving to age 18). The point estimates (represented in the figure as a grey square) are constructed by estimating equation (1) and converting the resulting coefficient $\beta$ to $\exp (\beta)$. The corresponding confidence intervals are represented as a horizontal line. The size of each square indicates the weight of each reform in the pooled estimation (with larger squares indicating a higher weight). The ${ }^{2}$ statistic (in percentages) reflects the degree of heterogeneity of estimates. According to the $p$ value, we cannot reject the null that there is no heterogeneity across studies. The pooled estimate (using fixed reform effects to construct the weights) is shown as the dashed line. 
Table A1: Reduced-form Estimates of Compulsory Schooling Reforms on 20-Year Mortality (Subset of Reforms with Reliable First-Stage)

\begin{tabular}{|c|c|c|c|c|c|c|c|}
\hline Country & Reform Year & \multicolumn{3}{|c|}{ Men } & \multicolumn{3}{|c|}{ Women } \\
\hline Netherlands & 1928 & 0.949 & 0.824 & 1.094 & 0.891 & 0.841 & 0.945 \\
\hline France & 1937 & & & & 1.082 & 0.954 & 1.226 \\
\hline Austria & 1966 & 0.935 & 0.876 & 0.998 & 1.026 & 0.953 & 1.104 \\
\hline France & 1967 & 0.951 & 0.927 & 0.976 & 0.967 & 0.918 & 1.018 \\
\hline Spain & 1970 & 0.984 & 0.939 & 1.032 & 1.018 & 0.934 & 1.108 \\
\hline Ireland & 1972 & 0.973 & 0.909 & 1.042 & 0.934 & 0.845 & 1.032 \\
\hline Pooled Estimates & & 0.974 & 0.957 & 0.992 & 0.978 & 0.949 & 1.008 \\
\hline
\end{tabular}


Table A2: Robustness Checks for Male 20-Year Mortality (Reduced-form Estimates)

\begin{tabular}{|c|c|c|c|c|c|c|c|c|c|}
\hline & & $\begin{array}{l}\text { Bandwidth }+/- \\
5 \text { cohorts }\end{array}$ & & $\begin{array}{c}\text { Bandwidth } \\
+/-3 \text { cohorts }\end{array}$ & & $\begin{array}{c}\text { Local Linear } \\
\text { Polynomial }\end{array}$ & & $\begin{array}{c}\text { Global Cubic } \\
\text { Polynomial }\end{array}$ & \\
\hline Belgium & 1919 & 0.957 & $(0.910,1.006)$ & 0.973 & $(0.921,1.029)$ & 1.025 & $(0.973,1.080)$ & 0.934 & $(0.861,1.013)$ \\
\hline Netherlands & 1928 & 1.127 & $(1.070,1.187)$ & 1.142 & $(1.070,1.219)$ & 1.242 & $(1.082,1.425)$ & 1.000 & $(0.862,1.161)$ \\
\hline France & 1937 & 1.395 & $(0.824,2.362)$ & 1.556 & $(1.095,2.211)$ & 0.953 & $(0.768,1.229)$ & 1.056 & $(0.846,1.317)$ \\
\hline Netherlands & 1950 & 1.033 & $(0.991,1.076)$ & 1.058 & $(1.023,1.096)$ & 1.060 & $(0.996,1.129)$ & 0.993 & $(0.904,1.092)$ \\
\hline Northern Ireland & 1957 & 0.925 & $(0.860,0.995)$ & 0.938 & $(0.881,0.997)$ & 0.957 & $(0.927,0.988)$ & 0.934 & $(0.894,0.975)$ \\
\hline Sweden & 1962 & 0.992 & $(0.929,1.060)$ & 0.962 & $(0.890,1.041)$ & 1.053 & $(1.005,1.103)$ & 1.002 & $(0.948,1.058)$ \\
\hline Italy & 1963 & 0.979 & $(0.891,1.077)$ & 0.987 & $(0.915,1.065)$ & 0.953 & $(0.911,0.997)$ & 1.010 & $(0.963,1.058)$ \\
\hline Austria & 1966 & 0.937 & $(0.848,1.035)$ & 0.929 & $(0.844,1.022)$ & 1.012 & $(0.961,1.065)$ & 0.958 & $(0.906,1.013)$ \\
\hline France & 1967 & 0.985 & $(0.962,1.008)$ & 0.983 & $(0.956,1.010)$ & 1.086 & $(1.034,1.142)$ & 0.982 & $(0.963,1.002)$ \\
\hline Denmark & 1971 & 1.024 & $(0.776,1.352)$ & 1.120 & $(0.945,1.327)$ & 0.961 & $(0.859,1.074)$ & 1.031 & $(0.901,1.181)$ \\
\hline Scotland & 1976 & 0.999 & $(0.948,1.052)$ & 0.991 & $(0.936,1.050)$ & 0.948 & $(0.919,0.978)$ & 0.937 & $(0.888,0.990)$ \\
\hline
\end{tabular}

Notes: The table shows reduced-form estimates of the compulsory schooling reforms on 20 -year mortality for men using four alternative specifications. The first two use only 5 and 3 cohorts above and below the threshold when estimating equation (1). The second two specifications use a local linear polynomial and a global cubic polynomial to adjust for mortality trends. The numbers (in columns labeled "OR") are the coefficients on the reform dummy $\beta$ (from estimating equation(1) separately for each country) converted to exp( $\beta$ ). The numbers thus represent the effect on the odds of dying (and not the log odds ratio as in equation (1)). The upper and lower bound of the corresponding $95 \%$ confidence intervals are reported in brackets next to the estimate. The pooled estimate is from a meta-analytic model using random effects to construct weights for each reform (see Section 3.3 for further details). Statistically significant effects are marked in bold. 
Table A3: Robustness Checks for Female 20-Year Mortality (Reduced-form Estimates)

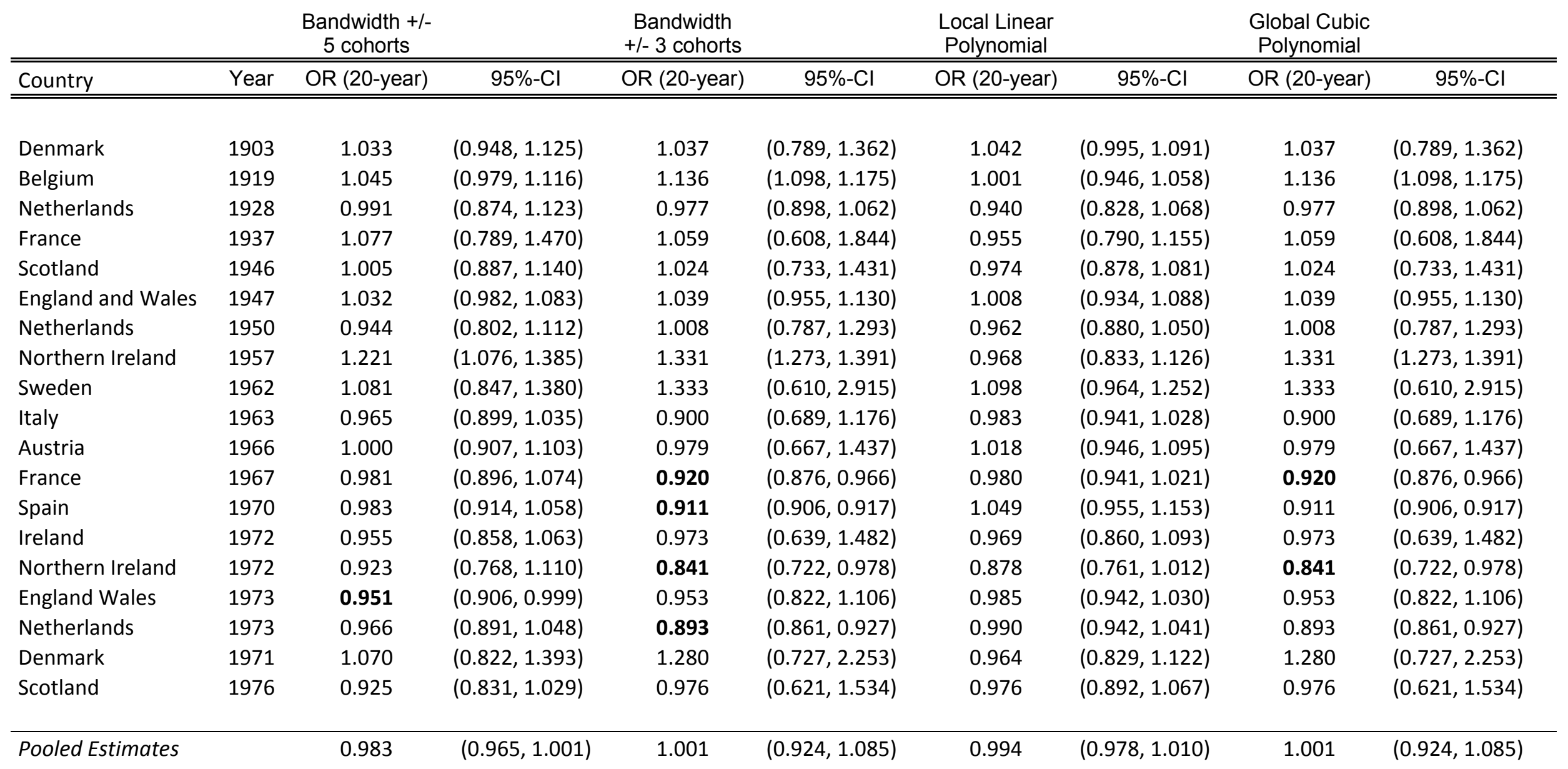

Notes: The table shows reduced-form estimates of compulsory schooling reforms on 20-year mortality for women using four alternative specifications. The first two use only 5 and 3 cohorts above and below the threshold when estimating equation (1). The second two specifications use a local linear polynomial and a global cubic polynomial to adjust for mortality trends. See notes to Table A2 for further details. Statistically significant effects are marked in bold. 
Figure A1: Reduced-form Effects on 20-year Mortality Rates (Men) with 1975 for Danish Reform

Country

(Year of Reform)

Estimate $(95 \% \mathrm{Cl})$

Denmark (1903)

Belgium (1919)

Netherlands (1928)

France (1937)

Scotland (1946)

EnglandWales (1947)

Netherlands (1950)

Northernlreland (1957)

Sweden (1962)

Italy (1963)

Austria (1966)

France (1967)

Spain (1970)

Ireland (1972)

Northernlreland (1972)

EnglandWales (1973)

Netherlands (1973)

Denmark (1975)

Scotland (1976)

Overall $(\mathrm{I}$-squared $=43.1 \%, p=0.024$ )

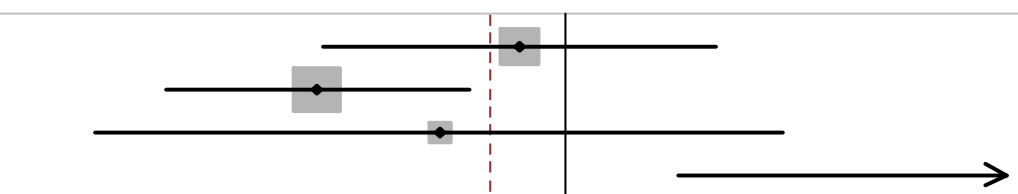

$0.982(0.905,1.065)$

$0.903(0.848,0.961)$

$0.949(0.824,1.094)$

$1.348(1.048,1.734)$

$1.016(0.942,1.096)$

$0.935(0.783,1.116)$

$0.981(0.913,1.054)$

$0.926(0.871,0.983)$

$0.983(0.919,1.052)$

$1.025(0.969,1.085)$

$0.935(0.876,0.998)$

$0.951(0.927,0.976)$

$0.984(0.939,1.032)$

$0.973(0.909,1.042)$

$0.943(0.864,1.029)$

$0.984(0.971,0.998)$

$1.027(0.959,1.100)$

$0.931(0.812,1.068)$

$0.938(0.885,0.994)$

$0.970(0.952,0.987)$

.9

95

1.05

11

1.2

Notes: The figure summarizes the reduced-form effects of 19 compulsory schooling reforms on the odds of men dying between the ages 18 and 38 (conditional on surviving to age 18). The point estimates (represented in the figure as a grey square) are constructed by estimating equation (1) and converting the resulting coefficient $\beta$ to $\exp (\beta)$. The corresponding confidence intervals are represented as a horizontal line. The size of each square indicates the weight of each reform in the pooled estimation (with larger squares indicating a higher weight). The $\mathrm{I}^{2}$ statistic (in percentages) reflects the degree of heterogeneity of estimates. According to the $p$ value, we can reject the null that there is no heterogeneity across studies. The pooled estimate (using random reform effects to construct the weights) is shown as the dashed line. 
Figure A2: Reduced-form Estimates on 20-year Mortality Rates (Women) with 1975 for Danish Reform

Country

(Year of Reform)

Estimate $(95 \% \mathrm{Cl})$

Denmark (1903)

Belgium (1919)

Netherlands (1928)

France (1937)

Scotland (1946)

EnglandWales (1947)

Netherlands (1950)

Northernlreland (1957)

Sweden (1962)

Italy (1963)

Austria (1966)

France (1967)

Spain (1970)

Ireland (1972)

Northernlreland (1972)

EnglandWales (1973)

Netherlands (1973)

Denmark (1975)

Scotland (1976)

Overall $(\mathrm{I}$-squared $=53.0 \%, p=0.004)$

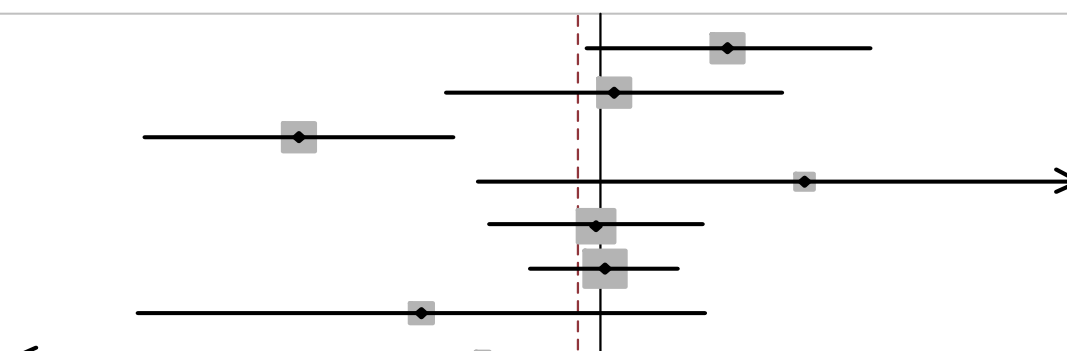

$1.050(0.995,1.108)$

$1.005(0.943,1.072)$

$0.891(0.841,0.945)$

$1.082(0.954,1.226)$

$0.999(0.959,1.040)$

$1.002(0.974,1.031)$

$0.935(0.839,1.041)$

$0.957(0.799,1.146)$

$\rightarrow 1.115(0.981,1.267)$

$0.983(0.931,1.038)$

$1.026(0.953,1.104)$

$0.967(0.918,1.018)$

$1.018(0.934,1.108)$

$0.934(0.845,1.032)$

$0.878(0.791,0.975)$

$0.994(0.956,1.034)$

$0.995(0.940,1.054)$

$1.136(1.012,1.275)$

$0.986(0.912,1.065)$

$0.992(0.970,1.014)$

$\begin{array}{lllllllll}8 & .85 & 9 & .95 & 1 & 1.05 & 1.1 & 1.15 & 1.2\end{array}$

Notes: The figure summarizes the reduced-form effects of 19 compulsory schooling reforms on the odds of men dying between the ages 18 and 38 (conditional on surviving to age 18). The point estimates (represented in the figure as a grey square) are constructed by estimating equation (1) and converting the resulting coefficient $\beta$ to $\exp (\beta)$. The corresponding confidence intervals are represented as a horizontal line. The size of each square indicates the weight of each reform in the pooled estimation (with larger squares indicating a higher weight). The $I^{2}$-statistic (in percentages) reflects the degree of heterogeneity of estimates. According to the $p$ value, we can reject the null that there is no heterogeneity across studies. The pooled estimate (using random reform effects to construct the weights) is shown as the dashed line. 